\title{
Applied Cleaning Methods of Oil Residues from Industrial Tanks
}

\author{
Alexandros Chrysalidis and George Z. Kyzas *D \\ Department of Chemistry, International Hellenic University, 65404 Kavala, Greece; alchrys17@yahoo.com \\ * Correspondence: kyzas@chem.ihu.gr; Tel.: +30-2510-462218
}

Received: 14 April 2020; Accepted: 8 May 2020; Published: 11 May 2020

\begin{abstract}
The oil industry is facing a major problem with the large amount of oil residue generated in the tanks that store and process crude oil or its products. Research has shown that the residues of petroleum sludge, which according to a sample from the Azzawiya oil refinery in Libya mainly consist of oil, water and solid residues in $42.8 \%, 2.9 \%$ and $55.2 \%$ respectively, result in the alteration of the product quality and reduced capacity of the tanks. The solution for this problem as well as the need for inspection and maintenance requires the removal of this oil sludge and the internal cleaning of the tanks. This report aims to review the applied clean-up methods available in the world market and to identify the most efficient, safest, most economical and most environmentally friendly cleaning process. It must be noted that until now, there is not any published work which presents the applied techniques. To accomplish this goal, a total of five manual, automatic and robotic cleaning systems were analyzed and evaluated according to their advantages and disadvantages. The results show that the MEGAMACS with sludge extractor automatic cleaning system with an output of $14.8 \mathrm{~m}^{3} / \mathrm{h}$ is the fastest cleaning system, while the MARTin where the presence of people inside the tank is not necessary at any stage is the safest. In terms of cleaning costs and environmental impact, the automated BLABO, COW and MEGAMACS systems as well as the MARTin robotic system are the most economical and environmentally friendly due to the closed cleaning circuit and the ability to recover up to $95 \%$ of the oil from the sludge, which is returned to the customer and the earnings cover the costs of cleaning. The conclusion drawn is that the current need in the oil industry, in the field of tank cleaning, is the use of high-efficiency automatic or robotic cleaning methods, which aim to reduce the tank downtime, without the need for staff entrance into a permit-required confined space and with the ability to recover up to $100 \%$ of the hydrocarbons present in the composition of the sludge.
\end{abstract}

Keywords: tank cleaning; oil residues; petroleum sludge; cleaning methods; crude oil tank bottom residues; manual cleaning; automated cleaning; robotic cleaning

\section{Introduction}

The oil industry is facing a major problem with the large amount of oil residue generated in the tanks that store and process crude oil or its products. This report aims to review the applied clean-up methods available in the world market and to identify the most efficient, safest, most economical and most environmentally friendly cleaning process. It must be noted that until now, there is not any published work which presents the applied techniques, but only a discussion developed at the theoretic and basic levels. In this report, we aim to analyze the most-widely known applied methods.

\subsection{Industrial Tanks for Oil Storage}

In the oil industry, there are various types of tanks, vessels and pits that store or process fluids which contain oil in their composition. One of them is the crude oil tank, which can be seen in 
Figure 1 [1] and is used for the storage of crude oil. A crude oil tank can be a bolted steel tank (API 12B), a welded steel tank (API 12F-BS 2654), a flat-sided (API 620) or a Field-welded (API 12D-API 650) tank. It is usually made of carbon steel which is capable of external and/or internal painting, galvanized coating or polymeric coating for corrosion protection. The tank type, dimensions and material vary depending on the storage conditions of the oil (pressure, temperature), the properties of the crude (composition, toxicity) and the amount of storage required $\left(\mathrm{m}^{3}\right)$. Its main parts are the shell, bottom, roof (fixed or floating), nozzles, pipelines and instruments, cathodic protection system and steel structures for the service of the staff.

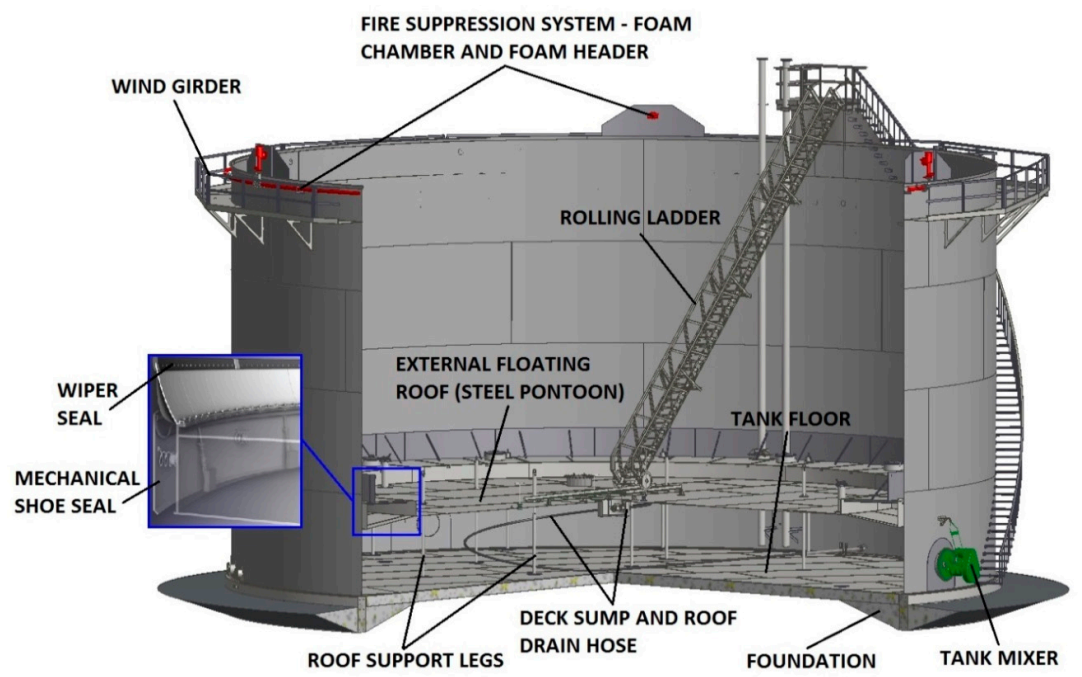

Figure 1. External floating roof tank cross-section [1].

The roof can be fixed or floating. The floating roof may be internal in combination with a fixed roof (occurring in cases of increased snowfall or rain for long periods of time that burden the floating roof exposed to the environment) or external. The floating roof floats on the oil inside the tank with the help of pontoons that exist outside the perimeter. Isolation of oil with the environment is achieved by sealing the perimeter between the roof and the shell with a double sealing system, which prevents the oil from leaving the tank and the entry of any fluid or solid into the tank but allows the roof to move freely up and down [2]. The main advantage of a floating roof is that it comes in direct contact with the oil inside the tank, thereby reducing vapor formation, and also reduces the risk of fire and corrosion caused by the presence of air. The remaining parts of the floating roof are the supports, the vents, the drains, the manholes and the gauges. Attached to the shell there are several nozzles servicing various needs, such as filling and emptying, cleaning, installation of equipment (agitators, valves and gauges), manholes for staff entry, etc. There is also a fire safety network installed on the roof of the tank in case of fire. A cathodic protection system is also installed on the tank bottom to prevent the galvanic corrosion.

\subsection{Cleaning of Industrial Oil Tanks}

Cleaning industrial tanks, vessels and pits containing petroleum residues is an inevitable process in the industry that companies must deal with. The main reason for cleaning is the residues created over time by the settling of the heavier elements contained in petroleum [3]. These residues occupy considerable space in the tanks, reducing their capacity and altering the quality of the products. Apart from everything else we mentioned, there is also the need for some scheduled inspections which are required by the operating regulations. These activities cannot be carried out with the presence of residues inside the tank. Companies have focused on finding cleaning methods aimed at staff safety, cleaning efficiency, time/money savings and environmental protection. The methods that could be used to clean a tank could be manual, automatic (mechanical) and robotic. 
In most cases, staff entry inside the tank is required to complete the job, but the time spent in the tank and the number of people varies according to the procedure. Some of the goals for an effective clean-up are to reduce the number of staff entering a permit-required confined space because exposure to hazardous environments carries a number of risks, with studies showing an increased rate of accidents in recent years [4]. Also, the need to reduce cleaning costs and increase safety has focused on more automated methods that require less labor and have proven safer. Another major goal is to recover the oil contained in large percentages in the sludge residues that have been deposited at the bottom of the tank. A lot of case studies have shown that the revenue generated by oil recovered from sludge outweighs the costs of the cleaning operation. Moreover, with environmental regulations becoming stricter every year, the safe transportation and storage of the sludge, inside a closed loop circuit, and other cleaning waste from the tank to a specific site and from there to the waste treatment plants is also an important factor in an effective cleaning method.

\subsection{Composition of Tank Bottom Oil Residues}

Before cleaning a tank, an analysis of the tank residues is important in order to identify their chemical composition. The sludge at the nozzle of a tank, shown in Figure 2 [5], consists mainly of organic matter (hydrocarbons varying in quality of crude oil stored at times), water and mechanical impurities at different rates, according to the point of measurement in the tank.

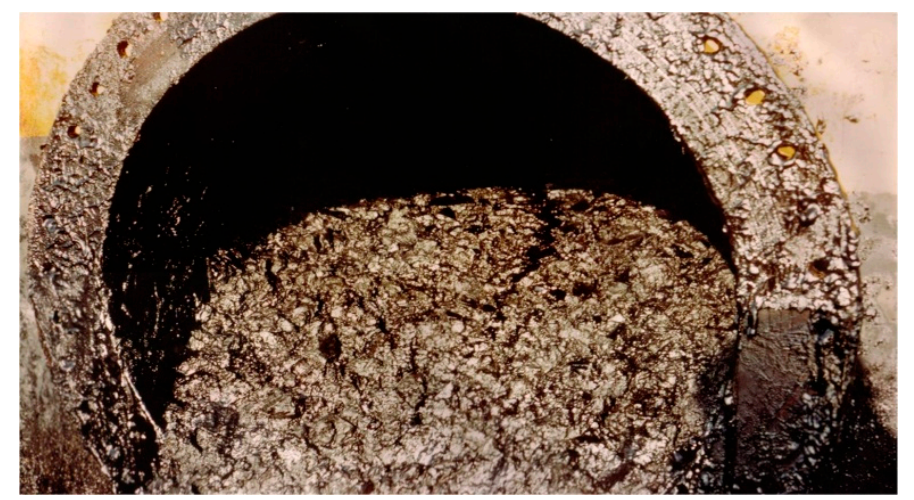

Figure 2. Crude oil tank bottom sludge [5].

The volume of sludge at the bottom is divided into three main layers. In the higher layer, there are plenty of hydrocarbons which are lighter than water. In the middle layer, there is mainly water, and in the lower layer are the solid residues [6]. Furthermore, the composition of the sludge is important to be investigated as it will be a key factor in the selection of the appropriate chemicals, solvents or extractants which must be used in some cases if they are required by the cleaning process. Also, the subsequent processes of the sludge for the recovery of the oil, the treatment of the wastewater and the solid residues contained therein require the composition of the sludge to be known.

The novelty of this report is the presentation of many cleaning methods and techniques in one research report, which provide better information prior to cleaning a tank. The conclusions drawn from the comparison of advantages and disadvantages provide a valuable evaluation guide for the one who is trying to decide which is the most appropriate cleaning method for a tank. From the detailed discussion, the need for improvement and innovation aimed at better practices in the future is illustrated.

\section{Crude Oil and Petroleum Sludge}

\subsection{Crude Oil}

The crude oil stored in the tanks is in liquid form and has some characteristic properties, such as: (i) dark black shading, intense smell (bisulfite), high viscosity, high flammability and lower density than that of water. Crude oil consists of complex chains of heavy hydrocarbons and may also contain 
light hydrocarbons and other elements in smaller quantities. The basic types of hydrocarbons that form crude oil are:

- Paraffins (Saturated Hydrocarbons-Alkanes (e.g., octane) with formula $\mathrm{C}_{\mathrm{n}} \mathrm{H}_{2 \mathrm{n}+2}$ )

- Olefins (unsaturated hydrocarbons-alkenes (e.g., pentene) with formula $\mathrm{C}_{\mathrm{n}} \mathrm{H}_{2 \mathrm{n}}$ )

- Naphthenes or cycloparaffins (Saturated Hydrocarbons-Cycloalkanes (e.g., cyclohexane) of general formula $\mathrm{C}_{\mathrm{n}} \mathrm{H}_{2}$ )

- $\quad$ Aromatic hydrocarbons (arenes (e.g., benzene))

The first three types of hydrocarbons (paraffins, olefins and naphthenes) are sometimes referred to as aliphatic compounds [7].

It is characterized as sweet or sour according to its sulfur content:

- Sweet crude oil: Sulfur $<0.5 \%$

- Sour crude oil: Sulfur $>0.5 \%$

Crude oil comes to the surface by the process of extraction from the ground and goes through various processing stages depending on its properties before being brought to storage tanks. The most critical and common process after the extraction is the removal of water and gases through three face separators and the desulphurization process [8], because the refineries need to receive crude oil without high sulfur content. There are several desulphurization methods, such as:

- Extractive desulfurization

- Oxidative desulfurization

- Biodesulfurization

- Desulfurization through alkylation

- Chlorinolysis

- By using supercritical water

So, it is then transferred to refineries by tankers and subjected to fractional distillation to separate its components and produce the finished products, as shown in Figure 3 [9].

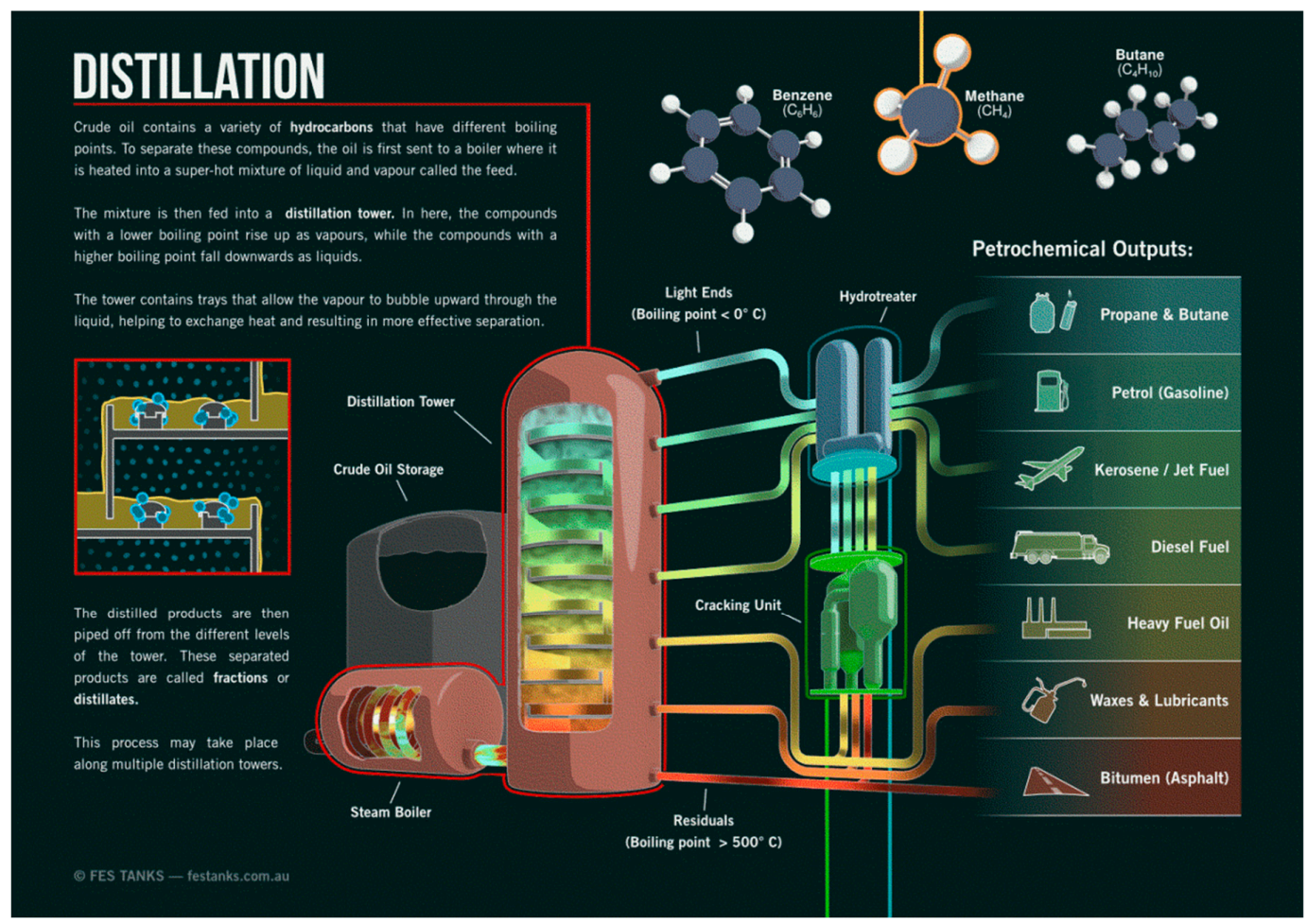

Figure 3. Distillation of crude oil [9]. 
The average composition of crude oil is shown in Table 1.

Table 1. Crude oil average composition.

\begin{tabular}{cc}
\hline Crude Oil Elements & Content $\%$ \\
\hline Carbon & $79.5-87.1$ \\
Hydrogen & $11.5-14.8$ \\
Sulfur & $0.1-3.5$ \\
Nitrogen & $0.1-0.5$ \\
Oxygen & $0.1-0.5$ \\
\hline
\end{tabular}

Sulfur, nitrogen, oxygen, porphyrins, asphaltenes and trace elements are referred to as non-hydrocarbon components of petroleum. Compounds containing nitrogen, sulfur or oxygen in their composition are also referred to as NSO compounds. Oil contains a very large percentage $(0 \%-20 \%)$ of high molecular weight materials $(1000-10,000)$, consisting of hydrocarbon compounds and NSO compounds, called asphaltenes. These heavy molecules cause problems not only to refining, but also to production and transportation. The amount of asphaltenes present in oil does not correlate with the amount of deposition. According to Leontaritis and Mansoori [10], oils with 17\% asphaltenes in their composition indicated less or zero deposition in the tubes than others with $0.4 \%$ to $9.8 \%$ or more. Asphaltenes precipitation is a function of many situations. Some of them are listed below [10-12]:

- Low resins-to-asphaltene ratios

- Temperature and pressure reduction

- Combining certain crudes

- Gas lifting (enhanced oil recovery (EOR) with natural gas or $\mathrm{CO}_{2}$ )

- Shear effects and electronic effects during flow

Speight [13] along with Leontaritis and Mansoori [10] have summarized some of the problems caused by asphaltenes: (i) formation damage, (ii) well bore plugging, (iii) pressure reduction, (iv) production blocking, (v) plugging the porous structure of the reservoir matrix (permeability reduction), (vi) reduced flow ability of the medium, (vii) interruption or cessation of the recovery operations, (viii) flow line (tubing) and production equipment plugging, (ix) emulsions formation with contaminating water, $(\mathrm{x})$ during crude oil and product storage: sedimentation and plugging induced by oxidation, (xi) sedimentation and coke formation upon heating, (xii) fouling in heated equipment and (xiii) catalyst deactivation during residue processing.

\subsection{Petroleum Sludge}

Petroleum sludge is one of the most common wastes that are produced from the oil industry [14]. Sludge can be defined as any material in a storage tank which will not flow under gravity to a suction point [5]. It is formed from the processing of the crude oil and precipitates inside tanks, vessels, pipelines and equipment, such as valves, heat exchangers, separators, etc., reducing their performance. It is a dark viscous sticky gel consisting of oil, water and solids. These depositions in various places have negative consequences, not only to the equipment and the process but also to the environment due to the toxic substances, and therefore, the removal and treatment is of great concern to the industry. The disposal of petroleum sludge directly to the environment is prohibited and specific treatment is required before any disposal action. The chemical composition of the petroleum sludge is not always standard and depends mainly on the composition of the parent crude oil. An average chemical composition of six selected petroleum sludge samples collected from the Petroleum Development Oman (PDO) [15] showed that carbon, hydrogen, nitrogen, sulfur, oxygen, water, ash and solids had normalized weight of $37.79 \%, 6.38 \%, 0.091 \%, 1.388 \%, 19.55 \%, 17.72 \%, 7.623 \%$ and $9.448 \%$, respectively. 
Heidarzadeh et al. [16] found that the mean concentration of total petroleum hydrocarbons (TPH) from a composed mixture of oily sludge obtained from the Tehran Oil Refinery (TOR) was $265,600 \mathrm{mg} / \mathrm{kg}$. The Gasoline range organic fraction in the TPH of the sludge samples was negligible, the diesel range organic fraction varied between $50 \%$ and $60 \%$ or $145,600 \mathrm{mg} / \mathrm{kg}$ and the oil range organic fraction turned out to be $45.2 \%$ or $120,000 \mathrm{mg} / \mathrm{kg}$. No polyaromatic hydrocarbons were found in the sludge. The concentration of moisture was found to be $28.3 \%$ and that of the heavy metals are listed in Table 2. Comparing the concentration of heavy metals in solids isolating from the sludge samples of TOR with those of PDO, a huge difference is noticed, which is due to the different nature and depositional environment of the parent crude oil. The comparison of the heavy metal concentrations of TOR sludge with the soil clean-up levels for petroleum hydrocarbons at industrial areas in some developing countries indicated that there is a need for further treatment of the TPH of the sludge before the disposal to the environment.

Table 2. Heavy metals' concentration of two different oily sludges.

\begin{tabular}{ccc}
\hline Metal & Petroleum Development Oman & Tehran Oil Refinery \\
\hline Zinc & $278 \mathrm{mg} / \mathrm{kg}$ & $6100 \mathrm{mg} / \mathrm{kg}$ \\
Lead & $91 \mathrm{mg} / \mathrm{kg}$ & $850 \mathrm{mg} / \mathrm{kg}$ \\
Nickel & $7.5 \mathrm{mg} / \mathrm{kg}$ & $2700 \mathrm{mg} / \mathrm{kg}$ \\
Cadmium & Not Found & $100 \mathrm{mg} / \mathrm{kg}$ \\
Chromium & $12 \mathrm{mg} / \mathrm{kg}$ & Not Found \\
Mercury & $3.5 \mathrm{mg} / \mathrm{kg}$ & Not Found \\
\hline
\end{tabular}

Johnson and Affam [17] found that the composition of petroleum sludge consists of hydrocarbons in the largest proportion, asphaltenes, paraffins, water and inorganic solids. Some critical causes of petroleum sludge formation are the changes in external conditions (temperature, pressure, moisture), the cooling below the cooling point, the evaporation of light ends, the mixing with incompatible materials and the introduction of water to form emulsions.

Furthermore, a characterization analysis of crude oil tank bottom sludge (COTBS) from the Azzawiya oil refinery in Libya conducted by Mansur et al. [18] indicates the composition of the pure COTBS (Table 3), the composition of the recovered oil from COTBS and other critical properties (Table 4), which allowed the comparison with the parent crude oil but also with other COTBS globally in order to examine the possibility of recycling the recovered oil from COTBS into the parent crude oil for environmental and economic reasons. Within the recovered oil, by using the gas chromatograph mass spectrometer method, we noticed 136 different hydrocarbon fractions in the range of C14-C24, from which $45.6 \%$ were aromatic compounds, $34.6 \%$ aliphatic compounds and $19.8 \%$ unknown compounds. The amount of total petroleum hydrocarbons $(29,367 \mathrm{mg} / \mathrm{kg})$ in the oil were found to be lower than those of Tehran Oil Refinery sludge $(265,600 \mathrm{mg} / \mathrm{kg})$, which indicated lower hydrocarbon content.

Table 3. Pure crude oil tank bottom sludge composition.

\begin{tabular}{cc}
\hline Element & Content (\%) \\
\hline Oil content & $42.8( \pm 1.1)$ \\
Light (volatile) h/c in the oil content & $30.7( \pm 0.07)$ \\
Non-volatile h/c in the oil content & $69.3( \pm 0.4)$ \\
Water content & $2.9( \pm 0.2)$ \\
Solid content & $55.2( \pm 0.6)$ \\
Organic matter in the solid content & $70( \pm 0.6)$ \\
\hline
\end{tabular}


Table 4. Properties of recovered oil from crude oil tank bottom sludge (COTBS).

\begin{tabular}{cc}
\hline Element & Content (\%) \\
\hline API Gravity & 33.03 \\
Density & $0.68 \mathrm{~g} / \mathrm{L}$ \\
Kinetic viscosity at $70 \mathrm{~F}$ & $7.01 \mathrm{cSt}$ \\
Kinetic viscosity at $100 \mathrm{~F}$ & $3.655 \mathrm{cSt}$ \\
Ash content & $0.007 \mathrm{~g} / \mathrm{g}$ oil \\
Salt content $(\mathrm{NaCl})$ & $2.30 \mathrm{mg} / \mathrm{L}$ \\
\hline
\end{tabular}

Al-Futaisi et al. [15] assessed the tank bottom petroleum sludge for alternative management techniques, such as fuel supplement and road material. The analysis of various sludge properties such as proximate analysis, ultimate analysis and energy content indicate that its properties are very similar with other fuels used by the cement industry and could possibly be used as a fuel supplement. Also, the toxicity characteristic leaching procedure (TCLP) utilized for the determination of the extract amounts from an aggregate-sludge mixture, which could be used for paving layer applications. All the extracts except from mercury were much lower in comparison to the established TCLP maximum limits set by the United States Environmental Protection Agency (US EPA), which could mean the tank bottom sludge is able to be used as a road material.

\section{Oil Tanks Cleaning Methods}

\subsection{General}

Tanks in the industry are built in order to operate for many years, accompanying a factory throughout its life. To achieve that, a tank which stores or processes petroleum liquids needs to be inspected (Figure 4) [19], maintained and repaired frequently to continue working in a safe and efficient manner. After some years of operating a crude oil storage tank, several residues begin to form internally due to the stabilization of heavier hydrocarbons.
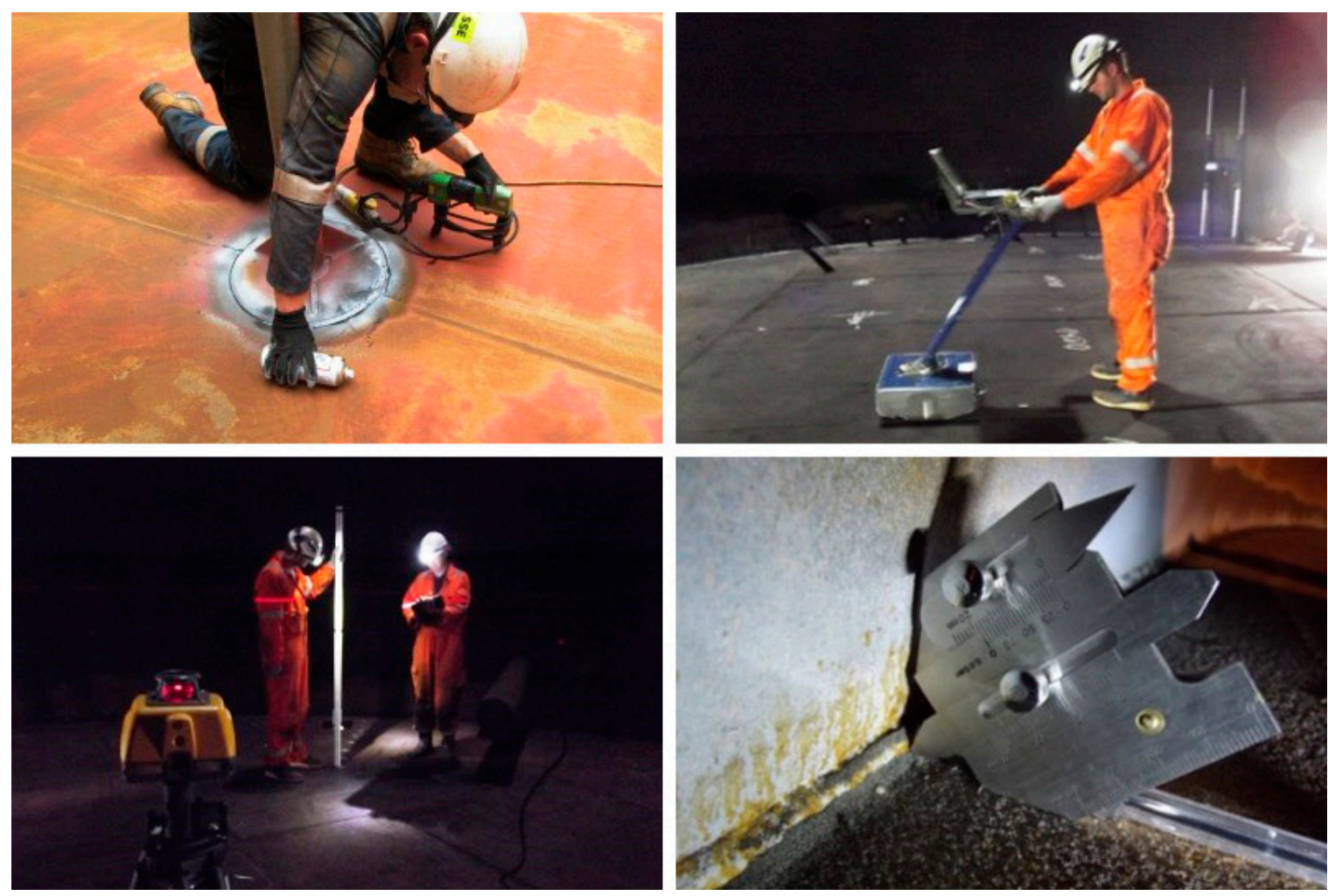

Figure 4. Tank inspection [19]. 
Those residues settle at the bottom of the tank along with water and solid particles which present in the crude oil composition and cause various problems like altering the quality of the stored product, reducing the storage capacity or even blocking the suction lines. All these objects coat the bottom, the shell and other various parts inside the tank, forming a slurry gel, commonly referred to as "petroleum sludge". This coating prevents interference with the metal parts of the tank, so in order to perform all the tasks mentioned above, like inspection and maintenance, the tank must be completely cleaned. Upon completion of cleaning, all surfaces of the tank (bottom, shell, ceiling, studs, tubing and various accessories) must be free of any dirt. The cleaning process, like all other activities to be carried out inside the tank, primarily requires the tank to be gas-free, for the safe entry of the personnel within the tank area and the safety of the premises. This is done in accordance with the standards and recommendations of the American Petroleum Institute (API) [20,21]. Commercially available cleaning methods are categorized into manual, automatic, chemical and mechanical. The selection of the appropriate method is judged by the owner's requirements, usually related to safety, cost, execution time and environmental conscience.

\subsection{Manual Cleaning}

Manual cleaning (Figure 5) [22] is one of the first methods used in the industry as it does not require any special technology or study. The equipment needed to complete the project is the simplest available in the market, and the staff to perform the task can be easily specialized. The driving force behind the process is the workforce which, using vacuum pumps or trucks, winches, trolleys, pressurized water and other simple mechanical means, tries to remove sludge with water and solid residues from the inside of the tank and store them in properly configured storage areas outside the tank [23].
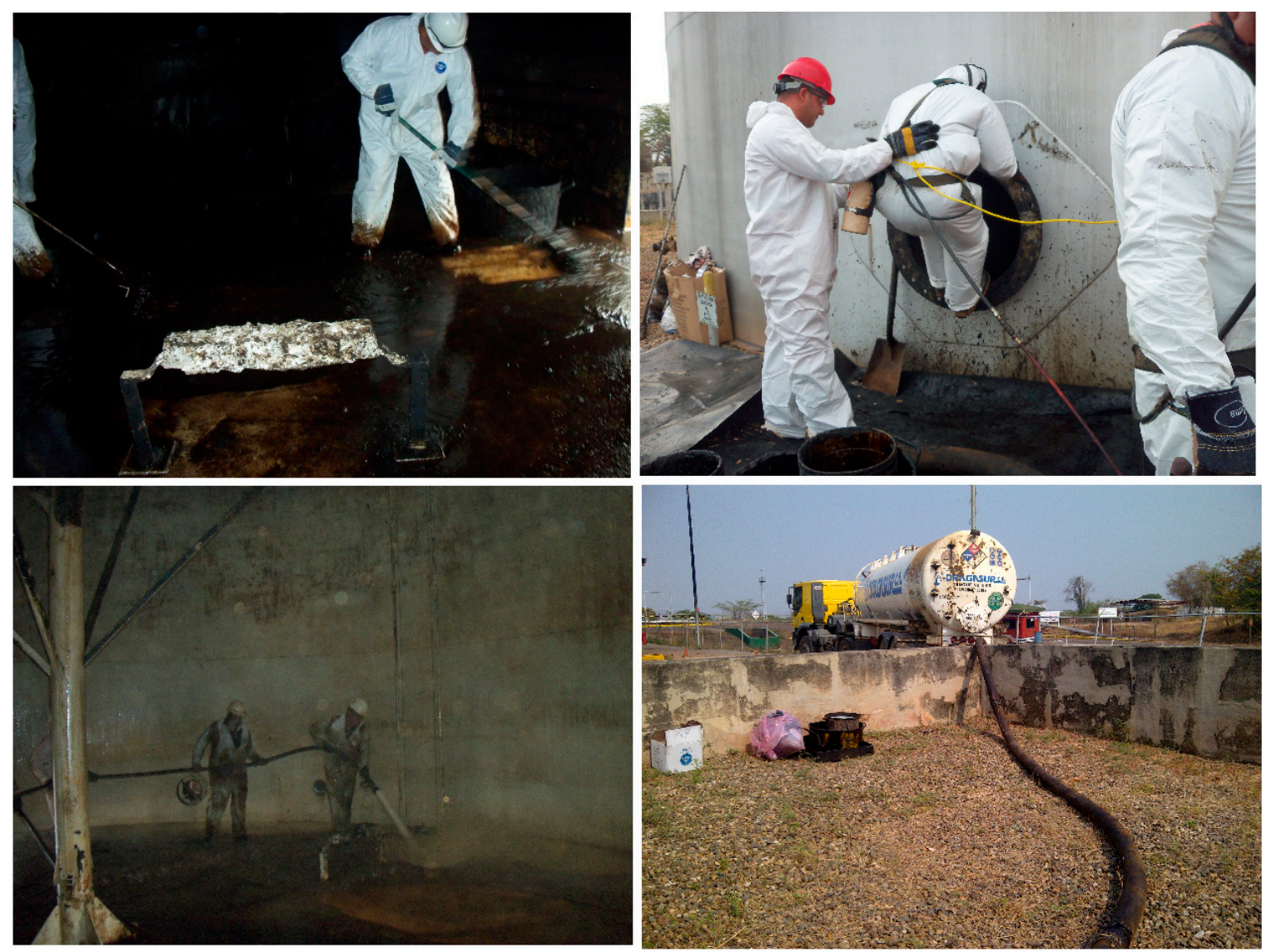

Figure 5. Manual cleaning of crude oil tank [22]. 
Subsequent treatment of residues (oil sludge) is not part of the cleaning process and could be carried out in a second phase from another company. All of this is a seemingly easy and inexpensive solution for cleaning a tank, but nonetheless, the method has often been criticized in recent years for displaying a large percentage of disadvantages, some of which are listed below:

- Low cleaning efficiency

- Work is conducted in a confined space

- Workers must wear heavy personal protective equipment with breathing apparatus

- Working is only possible for a few minutes

- Manual removal of the sludge

- Utilizing high-pressure water jetting

- The value of the oil is lost together with the sludge

- High amounts of waste (water, sludge, oil) are generated which need to be disposed of

- There is significant use of equipment and manpower

- Health and Safety Executive (HSE) concern applies during the job execution

- Downtime is huge

- Skilled workers for the job are limited and difficult to find

- Cost impact might be multiple times that of the mechanical cleaning cost

If there is a need to clean a tank, the executives will arrange a plan for the work to be carried out from the beginning to the end of the project. The main parts of the plan relate to safety (personnel, environment, facilities), the method to be used to carry out the project, the cost, the scope of work and the execution time. This process is followed almost before any industry activity and executives tend to choose the most efficient and safest solution.

Once the manual method is selected for cleaning the tank and the project is assigned to the appropriate contractor, the next step is to prepare for the start of work. This includes various seminars, updates on the methodology of the project implementation and safety lessons for those who are going to participate. Then, the organization of the construction site around the tank takes place. At this stage, the process of converting the tank to gas-free begins. In the tank, hot product (oil) is being recycled in order to soften the sludge and to be able to draw as much as possible from the suction system of the tank. By this technique, a small reduction of the sludge is achieved. Then, the tank is emptied, but still most of the sludge remains at the bottom. All manholes, cleaning doors and other openings on the roof are opened. Fans are then fitted to increase the supply of fresh air in order to speed up the process. Initially, the entrance is made using a respirator to obtain the necessary measurements. Measurements refer to percentages of explosive and toxic gases in the atmosphere as well as oxygen levels. As long as the necessary limits are met, the cleaning process is licensed and begins. The incoming personnel are provided with all the necessary safety equipment, such as waterproof disposable uniforms, boots, gloves, glasses, helmets, respirators, etc. The space inside the tank is adequately illuminated and observers and rescuers are positioned around the tank to observe people working inside the tank. The first problem that usually occurs is that the sludge is almost in a solid state, which makes it difficult to pump. To reduce the viscosity, high-pressure water is applied using pressurized water in conjunction with chemical solvents several times to reduce the surface tension of the sludge. When the sludge is converted into a pumpable liquid, it is transported outside the tank using vacuum trucks, or by pneumatic or volumetric pumps set in motion by hydraulic or electric ATmosphères EXplosives. (ATEX)-certified motors which send the liquid to predetermined points (usually cement ponds) [24]. After the total removal of the sludge, the tank needs to be cleaned again applying high-pressure water jetting along with the addition of environmentally compatible solvents [22]. This process is characterized by the difficulty of frequent manual movement and positioning of the vacuum suction hose at various points on the bottom of the tank. In addition, the residence time for working inside the tank is limited because it is carried out in a harmful environment. Personnel are replaced at intervals specified by international regulations and factory supervision. 


\subsection{Automated (Non-Human-Entry-Mechanical) Cleaning}

In recent years, the negative effects of manual tank cleaning have imposed stricter regulations on the industry on working in confined spaces with hazardous substances and protecting the environment. For this reason, the need for a more safe and harmless method of cleaning for humans, the environment and facilities gave birth to the automatic cleaning of tanks. Auto-cleaning began to flourish in commerce around the mid-20th century, with the main aim of eliminating human entry to work in confined spaces with a harmful atmosphere [25].

\subsubsection{ORECO's BLABO System}

One such system is described through ORECO A/S, which developed a portable automatic cleaning system called BLABO [26] that aims at a non-human entry cleaning method, capable of recovering up to $100 \%$ of the hydrocarbons present in the sludge composition. The process (Figure 6) [27] is carried out in a closed circuit in which the sludge at the bottom of the tank is first dissolved, sucked, separated and deposited.

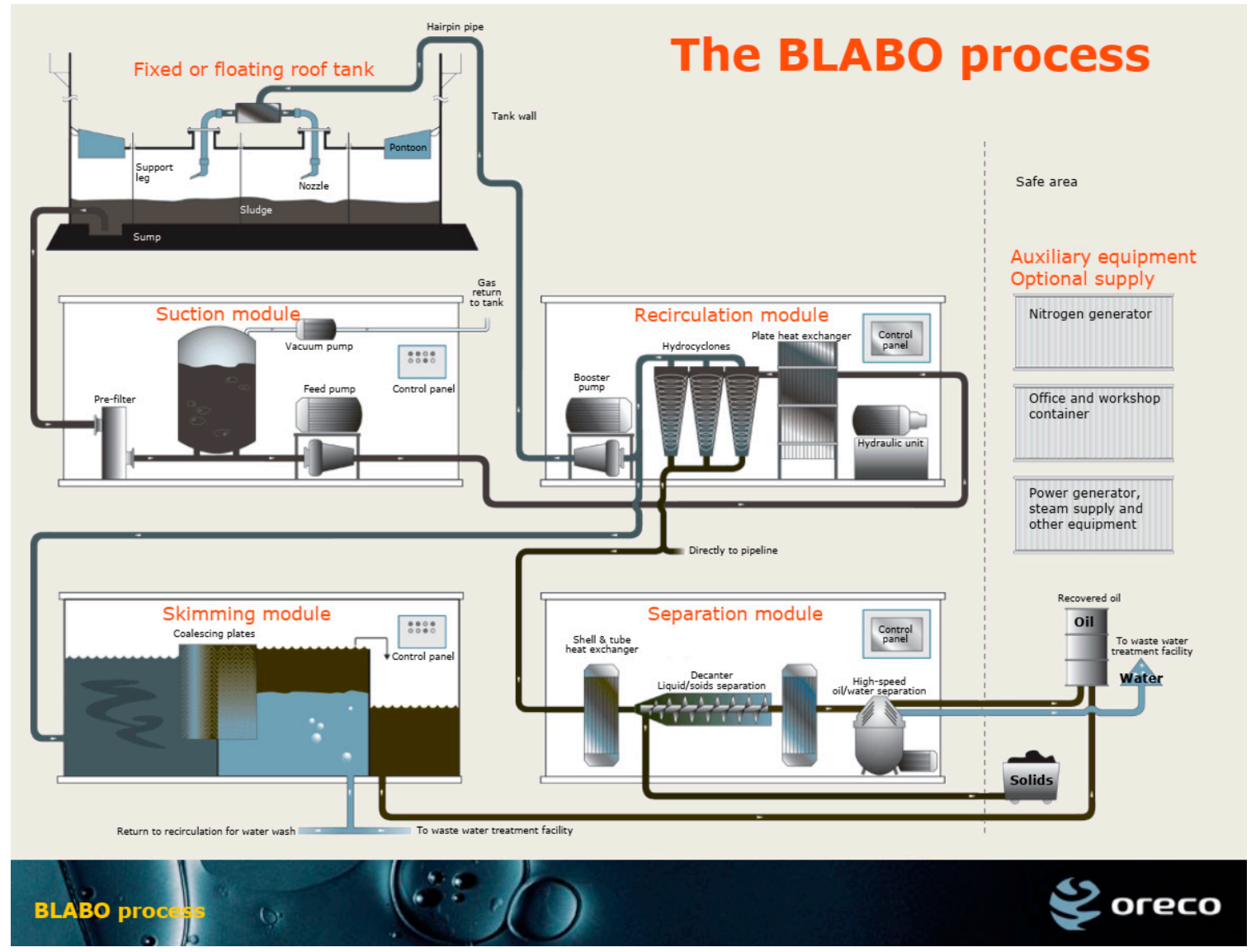

Figure 6. The BLABO process [27].

The inner surface of the tank is then flushed with water and delivered clean for inspection and maintenance. The process does not require human entry into the tank. Initially, the personnel transports and installs the equipment out of the tank according to the plan organized by the owner and the people of the cleaning company [28]. All equipment is integrated into containerized modules for easier transport and installation. The suction piping is connected through the already existing nozzles that the tank has installed on it, while openings are made on the roof, using the safe method of cold tapping, for the installation of the jetting nozzles and nitrogen supply pipes. To avoid the risk of explosion, the interior of the tank is filled with nitrogen until the oxygen content drops to $8 \%$. 
This value is constantly monitored by the monitor panels to keep it constant at this point. If for any reason this value exceeds the permissible limits, the process automatically stops until it returns to the default security point.

Then, once the equipment has been successfully installed, the operation is carried out by the control panels located on the modules in a safe area and at a distance from the tank. A key prerequisite for the transportation, installation and operation of the equipment is the use of qualified personnel trained by the company to certify the reliability, efficiency and safety of the process. In more detail, the system consists of a suction module, separation module, recirculation module, skimming module, jetting nozzles and auxiliary equipment. The main function of the suction module [29] is to suck the sludge from the bottom of the tank using vacuum pumps and centrifugal pumps and feed the recirculation module. To ensure the most efficient operation, the suction module is positioned as close as possible to the tank sump. Also, to avoid any blockage in the flow, two parallel filters are installed prior to pump suction. The operating panel, from which the module's operation can be adjusted, is installed on it. The recirculation module [30] is used for the desludging achieved by the recirculation of the cleaning media until the sludge is completely dissolved and removed from the inside of the tank. It is a focal point of the process as it involves the first separation of the heaviest sludge solids (powered by the suction module) through the three hydrocyclones installed, capable of delivering $43 \mathrm{~m}^{3} / \mathrm{h}$ each. The jetting nozzles [31], which are mounted on the roof of the tank, are the key to the process because they pass the cleaning media across the bottom of the tank and break up the sludge so that it can be easily sucked. Cleaning media is oil that originally existed in the sludge composition and was recovered during the separation process. The control panel controls the jetting nozzles and keeps the pressure on the outlet constant. In order to achieve a more efficient circulation, a heat exchanger is used to raise the temperature of the cleaning media and to facilitate flow. Lower explosive limit (LEL) and oxygen levels must also be obtained which must comply with safety regulations to maintain the safety of the process and to avoid any event of explosion or fire.

The separation module [32] operates simultaneously with the recirculation module. This module makes the final separation of the sludge according to the requirements of the tank owner. The mud can be separated into oil, water and solid residues, thus recovering almost $100 \%$ of the hydrocarbons present in it. The procedure is as follows: The separation module is powered by the recirculation module and the sludge initially passes through a shell and tube heat exchanger, which increases its temperature. It is then transferred to a two-phase decanter, where the solid residues are separated by the liquids. Solid waste is stored in containers for further treatment if required or disposed of directly to the environment if there are no restrictions by state regulations. The water-oil mixture passes through a second heat exchanger to result in a high-speed oil/water separator, where the final separation between oil and water takes place. The water is sent to the wastewater treatment facility while the oil is delivered to the owner as recovered oil to be sold or used in another process. At this point, there is no sludge left in the tank but only a thin layer of oil on the bottom and walls.

Complete cleaning of the tank requires a final flush with water to remove any residual oil on the walls and bottom of the tank. Hot water is used as cleaning media for this process, which is passed through the jetting nozzles. To ensure a more economical process and reduce consumption, the water used is recycled and separated from the oil and solid particles mixed with it during purification. This separation takes place in the skimming module [33], which is used exclusively at this stage. Separation is achieved by means of coalescing plates [34], which separate water from solids and oil in two stages. In the first stage, the solids are separated, and in the second, the oil is separated from the water. The water returns to the jetting nozzles to continue cleaning while the oil is sent for reprocessing. At this point, the cleaning process has come to an end and the manholes can be opened to vent the tank. Considering the results around the time and the performance of this system, the following table (Table 5) summarizes some of the work that has been done in the past according to ORECO's customer cases [35]. 
Table 5. ORECO's BLABO system case studies for crude oil tank cleaning.

\begin{tabular}{cccccc}
\hline Case Study & Tank Size & $\begin{array}{c}\text { Average } \\
\text { Sludge } \\
\text { Height }\end{array}$ & $\begin{array}{c}\text { Total } \\
\text { Sludge } \\
\text { Volume }\end{array}$ & $\begin{array}{c}\text { Total } \\
\text { Cleaning } \\
\text { Time }\end{array}$ & $\begin{array}{c}\text { Recovery } \\
\text { Rate }\end{array}$ \\
\hline Fawley Refinery (ESSO), UK & $18,300 \mathrm{~m}^{3}$ & $1.45 \mathrm{~m}$ & $1832 \mathrm{~m}^{3}$ & 15 days & $97.8 \%$ \\
VEBA Terminal, Ras Lanuf, Libya & $80,400 \mathrm{~m}^{3}$ & $4.5 \mathrm{~m}$ & $22,600 \mathrm{~m}^{3}$ & 121 days & $98 \%$ \\
Zueitina Terminal, Libya & $79,000 \mathrm{~m}^{3}$ & $0.85 \mathrm{~m}$ & $5300 \mathrm{~m}^{3}$ & 32 days & $94 \%$ \\
\hline
\end{tabular}

Furthermore, according to some case studies provided by VAOS Company [36], which uses the ORECOo's BLABO system for tank cleaning in Libya, Table 6 provides information about the performance.

Table 6. ORECO's BLABO system operated by VAOS for tank cleaning in Libya-Case studies.

\begin{tabular}{|c|c|c|c|c|c|}
\hline Client & Tank Size $\left(\mathrm{m}^{3}\right)$ & $\begin{array}{l}\text { HC Recovered } \\
\text { (USbbl) }\end{array}$ & $\begin{array}{c}\text { HC Recovered } \\
(\%)\end{array}$ & $\begin{array}{c}\text { Remaining HC } \\
\text { in Tank Before } \\
\text { Cleaning }\left(\mathrm{m}^{3}\right)\end{array}$ & $\begin{array}{c}\text { SNS } \\
\text { Operation (h) }\end{array}$ \\
\hline ZOC & 89,033 & 33,000 & 95.93 & 5469 & 624 \\
\hline VEBA OIL & 79,494 & 120,896 & 99.50 & 19,318 & 2496 \\
\hline RASCO & 79,494 & 110,327 & 99.71 & 17,592 & 1296 \\
\hline VEBA OIL & 79,494 & 38,428 & 99.04 & 6169 & 1560 \\
\hline ZOC & 158,987 & 38,267 & 98.12 & 6201 & 1632 \\
\hline VOO & 79,494 & 34,950 & 99.94 & 5560 & 1416 \\
\hline $\mathrm{ZOC}$ & 89,033 & 25,225 & 99.90 & 4014 & 816 \\
\hline $\mathrm{ZOC}$ & 89,033 & 12,000 & 97.17 & 1963 & 816 \\
\hline AGOCO & 79,494 & 14,472 & 99.12 & 2321 & 1272 \\
\hline $\mathrm{ZOC}$ & 89,033 & 40,254 & 99.89 & 6407 & 1344 \\
\hline ZOC & 89,033 & 23,502 & 97.93 & 3816 & 1176 \\
\hline ZOC & 41,337 & 1680 & 98.82 & 270 & 576 \\
\hline $\mathrm{ZOC}$ & 89,033 & 18,161 & 99.79 & 2893 & 696 \\
\hline ZOC & 89,033 & 44,218 & 99.93 & 7035 & 1128 \\
\hline SOC & 42,609 & 26,930 & 99.52 & 4302 & 1032 \\
\hline SOC & 42,609 & 18,130 & 99.62 & 2893 & 1032 \\
\hline $\mathrm{HOO}$ & 79,494 & 11,984 & 99.96 & 1906 & 648 \\
\hline SOC & 42,609 & 4695 & 99.89 & 747 & 312 \\
\hline SOC & 42,609 & 10,193 & 99.93 & 1622 & 672 \\
\hline SOC & 42,609 & 24,950 & 99.80 & 3975 & 1248 \\
\hline SOC & 42,609 & 24,717 & 98.56 & 3987 & 1440 \\
\hline $\mathrm{HOO}$ & 31,797 & 27,281 & 99.63 & 4353 & 1056 \\
\hline ZOC & 89,033 & 57,416 & 99.95 & 9133 & 888 \\
\hline
\end{tabular}

\subsubsection{Zaopin Technologies COW System}

The Zaopin COW system (Figure 7) [37] is an automatic crude oil tank cleaning system very similar to the BLABO system. The cleaning process consists of the following steps:

- Blanketing of the tank with nitrogen until the oxygen level drops below $8 \%$

- Liquefaction-disintegration of the sludge with recirculation oil (cleaning media) that is sprayed through cleaning nozzles

- Pumping the sludge from the bottom of the tank

- Separate the sludge from water-solids and recover the pure oil contained therein

- Final cleaning with water recirculation

- (Optional). Use a hydraulically powered specialized cleaning dozer that enters through a nozzle and is easily assembled in the tank and handled by only one person to remove the very heavy deposits that failed to be suctioned 
All equipment is installed in four 20 GP standard $6 \times 2.35 \times 2.8 \mathrm{~m}$ containers that can be easily transported by truck and installed near the tank. The modules are: (i) nitrogen generation unit and control room, (ii) oil/solids separation module, (iii) oil/water separation module and (iv) pipeline module. Once all the above equipment is connected to the tank, a number of high-impact cleaning cannons are installed on the roof or on the manholes located in the shell of the tank without any cold tapping. The number of cannons needed to fluidize the sludge range from 1 to 4 , depending on the size of the tank, and consist of a cleaning nozzle that can rotate $180^{\circ}$ along its vertical and horizontal axis, and a camera. After the tank is filled with nitrogen, produced by the autonomous nitrogen generation unit, and the oxygen content drops below $8 \%$, the cleaning nozzles operated by the control room begin to pump hot oil from the same or another existing tank, with pressure reaching 25 bar to start oil wash (desludging).

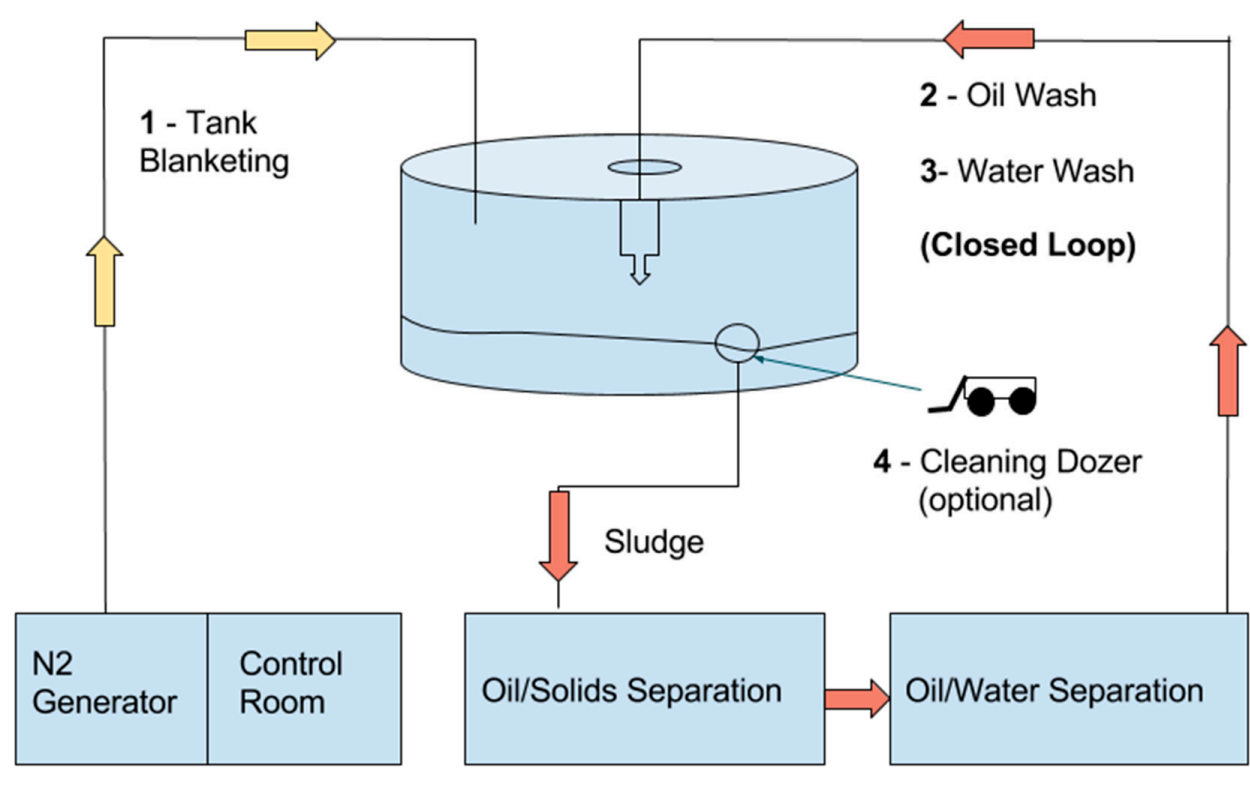

5 - Effluents: Oil, water, solids

Figure 7. The Zaopin COW system [37].

Subsequently, sludge is pumped through one of the various separation stages to remove valuable oil, water and solid residues. The valuable oil is stored in another tank for sale and the water that is separated from either the sludge or the washing water is recovered using a disc centrifuge and is sufficiently clean after separation to be immediately brought to the sewage treatment plant. Finally, the solid residues are recovered from the sludge through a decanter and can be given for incineration or special landfill disposal. Looking at the performance of the system, the maximum cleaning capacity is $150,000 \mathrm{~m}^{3}$, while the electricity consumption is ranging from 135 to $180 \mathrm{kwh}$. Looking at some recent projects [37], we observed the following information about the required cleaning time with the Zaopin COW system (Table 7).

Table 7. Zaopin technologies COW system case studies.

\begin{tabular}{cccccc}
\hline Customer & Tank Size & $\begin{array}{c}\text { Tank } \\
\text { Quantity }\end{array}$ & $\begin{array}{c}\text { Average } \\
\text { Sludge Height }\end{array}$ & $\begin{array}{c}\text { Total } \\
\text { Sludge Volume }\end{array}$ & $\begin{array}{c}\text { Total } \\
\text { Cleaning Time }\end{array}$ \\
\hline Sinopec Shanghai & $150,000 \mathrm{~m}^{3}$ & 8 & $5 \mathrm{~m}$ & $320,000 \mathrm{~m}^{3}$ & $60-65$ days \\
Formosa Plastic Group & $10,000 \mathrm{~m}^{3}$ & 4 & $0.5 \mathrm{~m}$ & $1400 \mathrm{~m}^{3}$ & 15 days \\
Sinopec Zhejiang Oilfield & $2000 \mathrm{~m}^{3}$ & 4 & $3 \mathrm{~m}$ & $1600 \mathrm{~m}^{3}$ & 8 days \\
Sinopec Wenzhou & $50,000 \mathrm{~m}^{3}$ & 2 & $0.5 \mathrm{~m}$ & $3000 \mathrm{~m}^{3}$ & 16 days \\
\hline
\end{tabular}

${ }^{1}$ Total cleaning time per tank, including assembly and disassembly of the equipment. 


\subsubsection{KMT's MEGAMACS system}

MEGAMACS [38] is a mobile, energy-independent system with its equipment stored in two containers that could be transported by truck. It can be used to clean hydrocarbons or hydrocarbon-contaminated materials that can be found in vessels, tanks, pits, oil tankers, barges, ponds, lakes and other reservoirs. The sludge removed is separated into oil, water and solid residues. Oil recovered from the sludge returns to the tank owner for sale, thereby converting it into net worth. The system can be installed up to $150 \mathrm{~m}$ away from the tank to be cleaned, resolving the frequent problems that arise due to space limitations. In addition, the procedure is performed with greater security. The equipment occupies only $70 \mathrm{~m}^{2}$ and does not require the ground to be specially designed for mounting, thanks to its versatile hydraulic system for adapting to rough terrain. It takes only 5 people to move the equipment and only $4 \mathrm{~h}$ to install it without the use of a crane. The system consists of heat exchanger, vibro-separator, main process tank, main washing pump, mud pump, vacuum system, tri-phase centrifuge, light-phase pump and oil collection tank, water pump and water collection tank, sludge extractor, high-pressure robotic cannon, auxiliary equipment, washing heads and booster pump.

Once all the equipment has been transported and installed in the appropriate place, as agreed to by the customer (Figure 8) [39], the main process tank is filled with $30 \mathrm{~m}^{3}$ of water, which is heated to $85^{\circ} \mathrm{C}$ through a spiral tube heat exchanger. Water is recycled using a single stage centrifuge pump, called a washing pump. This pump switches mode as soon as the water (or other cleaning media) catches the appropriate temperature and transfers it to the tank to be cleaned. Then, since the level of sludge in the tank is below the height of the manhole, the robotic tank cannon and the booster pump are placed inside the tank. Alternatively, the robotic tank cannon can also be mounted on the roof of the tank. If the sludge level is above the height of the manhole nozzle, then it is opened up to a point and actions are then taken to remove as much of it as possible to create sufficient space for the booster pump and the robotic tank cannon installation. This procedure may require the temporary installation of the robotic tank cannon at the manhole port.

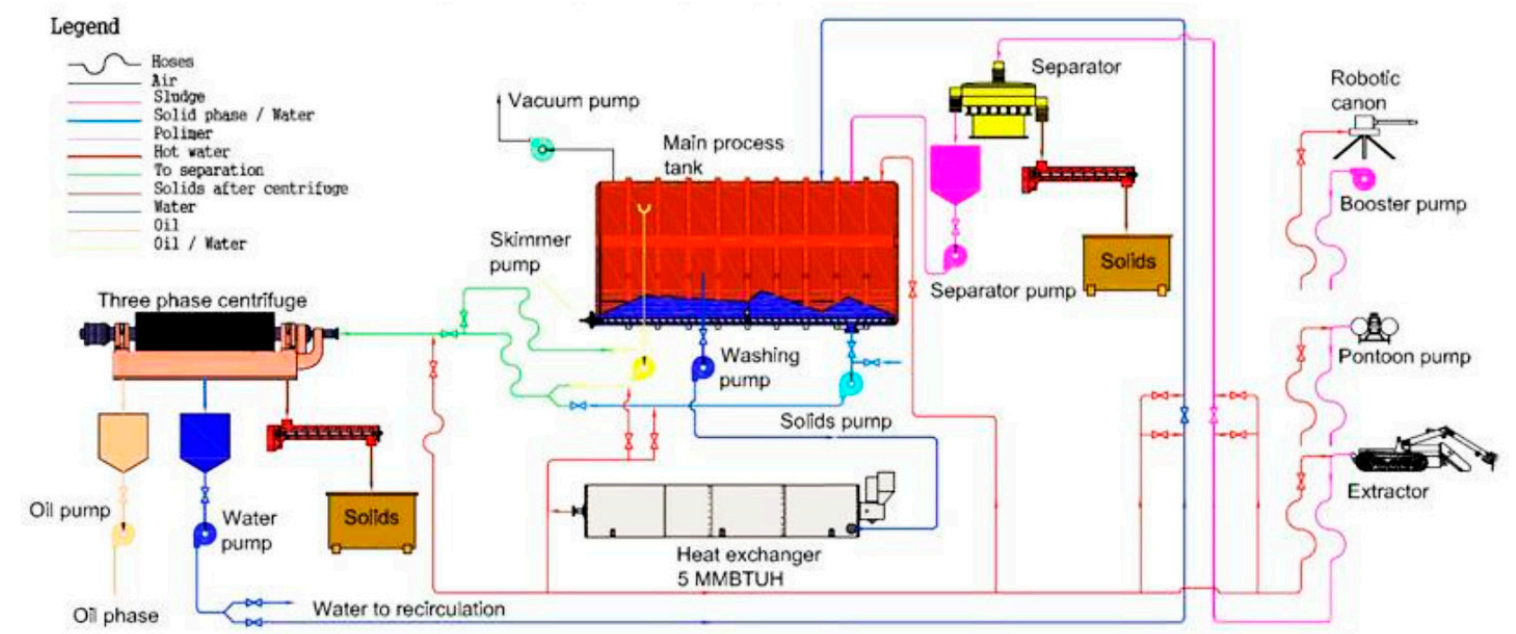

Figure 8. Tank cleaning, MEGAMACS process flow chart [39].

When the robotic tank cannon [40] is placed at the appropriate point in the tank, it starts to spray hot water or other cleaning media at a pressure of up to 20 bar in order to break up the sludge, which has either solidified or hardened, so that it can be easily sucked from the booster pump. It is a hydraulically actuated drive mechanism and the flow direction can be operated from the outside of the tank. The booster pump [40] is placed inside the tank and sucks the sludge together with the solid residues by sending them to the main cleaning unit. The pump can be submerged in the sludge without causing any damage because it is driven by hydraulic energy. The oil-water-solid mixture 
(sludge) is then passed to the vibro-separator, where the initial separation of the solid particles larger than $6 \mathrm{~mm}$ is made. These particles are stored in special containers and sent for further processing and storage. The remaining mixture of water-oil and small particles goes into the main process tank. There, the next separation takes place, with the solid particles settling on the bottom and on the surface remaining at a lighter fraction, consisting of $60 \%$ oil and $40 \%$ water.

According to MEGAMACS, this blend can be exploited in two ways. The first is to be sold as a final product commercially, while the second is to be sent to the tri-phase centrifuge for further separation. If the latter occurs, then a floating skimmer pump in conjunction with a solid pump drives the feed material into the tri-phase centrifuge unit. Both pumps are of progressive cavity type with hydraulic drive and output of $100 \mathrm{gpm}$ at $87 \mathrm{psig}$ [41]. The mixture leaving the tri-phase separator [42] consists of three phases of water-oil and solids. The oil's quality is quite good, with a content of up to $95 \%$, so it can be sold at a reasonable price, while the water can be pumped to the plant's water treatment unit or returned to the tank for more water flush. The solids are stored and transported for deposition or additional processing. In some cases where the tank is large, the sludge extractor [40] may be used instead of the robotic tank cannon and booster pump to remove the sludge from the bottom of the tank and transport it to the main cleaning unit. The vehicle is easily disassembled into lightweight pieces so that it can easily enter and exit the manhole. Once all the pieces have gone through it, the necessary assembly time is $2 \mathrm{~h}$. It is driven using hydraulic force. Only one operator is required to operate the vehicle in the tank. Two independent powered track drives are used to drive the machine inside the tank. The arm at the front excavates the sludge and drives it to the screw pump suction, which is fitted with it. At this point, the sludge is mixed with water and is liquefied in order to be pumped easily out of the tank. Looking at the performance of this system based on the specification provided by MEGAMACS, the following table (Table 8) shows the results.

Table 8. MEGAMACS tank cleaning system performance.

\begin{tabular}{ccc}
\hline Case & $\begin{array}{c}\text { Sludge Removal } \\
\text { Performance }\end{array}$ & $\begin{array}{c}\text { Sludge Recycling } \\
\text { Performance } \\
\text { (Oil-Water-Solids) }\end{array}$ \\
\hline $\begin{array}{c}\text { Robotic tank cannon and booster pump } \\
\text { Sludge extractor }\end{array}$ & $7 \mathrm{~m}^{3} / \mathrm{h}$ & $15 \mathrm{~m}^{3} / \mathrm{h}$ \\
\hline
\end{tabular}

As for system security, this system is designed to operate from up to $150 \mathrm{~m}$ away. Also, there is no need to use electricity at all, thus reducing the risk of explosion by spark or fire in the tank. All moving and rotating components are covered to prevent any accident. The control panel of the cleaning system is directly connected to the tank to monitor at any time certain operating parameters, such as appropriate atmosphere in the tank (lower explosion level, toxic gases, oxygen level, hydrocarbons concentration) and proper grounding of the tank to the ground. Should one or more operating parameters have exceeded the permissible operating limits, then the cleaning process automatically shuts down after the warning alarms are activated thanks to its automatic control system. Furthermore, because the system does not produce static electricity, it is not necessary to inert the tank. But, if requested by the customer for any reason, then KMT can provide such nitrogen supply equipment to meet this need. Regarding the consumption of the system (main unit and tri-phaser), it ranges from 30 to $50 \mathrm{~L} / \mathrm{h}$ of diesel.

\subsection{Robotic Cleaning}

Robotic cleaning is a new technology that has been applied in the oil industry for cleaning tanks, vessels, pits and other reservoirs in recent years. It is not the most common choice, as it is still in its infancy and its many advantages have not been made known worldwide to gain the confidence of tank owners. Nevertheless, the room for development is great. It came from the common need to avoid exhaustive manual human labor in confined spaces, with a harmful atmosphere that poses many dangers. This method replaces human labor with a self-directed cleaning method that does not require 
permanent presence of persons inside confined spaces (e.g., a tank) as equipment is handled from the outside. The robotic cleaning system is usually removable and houses the necessary equipment in containers that are easily transported by truck. The key to the process is the remote-control vehicle [43] that enters enclosures and is used to break up and remove sludge from the bottom of the tank. The basic vehicle components are listed below: cylinder, hydraulic motor, proportional solenoid valve, explosion-proof-type combustible gas detector, explosion-proof junction box, flow control solenoid valve, explosion-proof infrared lamp, explosion-proof/dust ignition proof camera, wipers, water jet, pan-tilt-zoom camera (PTZ) and shoveling.

The vehicle enters the tank manhole and can move across the bottom surface to suck or mechanically transport the sludge out of the tank. The vehicle is operated by an experienced specialized operator who drives the vehicle from a remote-control panel [44] outside the tank to a safe area. Using this method does not require the tank to be gas-free to enter the vehicle. Therefore, to eliminate any possibility of explosion or fire, all components fitted to the vehicle are anti-explosive and hydraulically driven. The hydraulic force is generated outside the tank and transported to the vehicle to drive its components through high-pressure hoses integrated on the vehicle. The vehicle can be easily disassembled and assembled so that it can easily enter and exit the tank. The sludge removed from the tank goes through several stages of purification to separate it into petroleum water and solid residues. It is a removable system consisting of equipment installed outside the tank at a distance from it and equipment that enters the tank. The following are installed outside the tank: centrifugal pumps, suction pumps (vacuum pumps), hydraulic and power-generating machines, sludge separation systems (in oil, water and solid residues) (optional) and remote-control and monitoring center. On the other hand, the following are installed inside the tank: remote-control vehicle with built-in water jet (or other cleaning media) for liquefaction or sludge splitting and monitoring system (live camera).

\section{MIRRICO's MARTin Oil Tech System}

A more detailed description of this cleaning method is made through the MARTin system, which is a very common cleaning method with that of MEGAMACS. MARTin Oil tech is an innovative robotic unit for cleaning oil tanks. The difference between this system and all previous cleaning systems is that it is fully automated. MARTin developed this capability by designing a robotic scavenger (Figure 9) [45] equipped with video surveillance and lighting systems, a discharge device and a detergent supply device that can be operated by an operator, outside the tank, through a specially designed space in the control room. Briefly, the complex of this cleaning system consists of the following blocks:

- Block for bottom sediments' extraction and washing of internal surfaces from oil deposits

- Block for cleaning and processing (phase separation) of sediments

- Block for storage and transportation of additional equipment and bandaging materials.

- A fourth block for the disposal (neutralization) of oil waste and water treatment is under development by the "MIRRICO" Group [46].

The blocks (trailers) [45] are the same size and weight and are transported by trucks to the installation site, which can be up to $150 \mathrm{~m}$ away from the tank to be cleaned. The sludge recycling process [47] is like the method described earlier by analyzing the MEGAMACS process so it will not be described. According to MARTin, the performance with which the robotic excavator can remove sludge from the tank is not less than $10 \mathrm{~m}^{3} / \mathrm{h}$, and from the process scheme, it is observed that it could reach $90 \mathrm{~m}^{3} / \mathrm{h}$ while ensuring high-quality of separation of the recovered oil sludge into oil, water and cake, at a 40 tones $/ \mathrm{h}$ production rate. This means that with an average sludge density of $1000 \mathrm{~kg} / \mathrm{m}^{3}$, the bottom sediments' recycling capacity is $40 \mathrm{~m}^{3} / \mathrm{h}$. It is an autonomous diesel generator but could also work with electricity as an energy source. For installation it requires only 5 people and $4-6 \mathrm{~h}$, without the need for a crane and proper aligned ground. The rooms are equipped with lights, heating, air conditioning and are very well insulated, so it can work in environmental conditions from -30 to $+45^{\circ} \mathrm{C}$. It can clean tanks with size from 500 to $100,000 \mathrm{~m}^{3}$ [48]. 

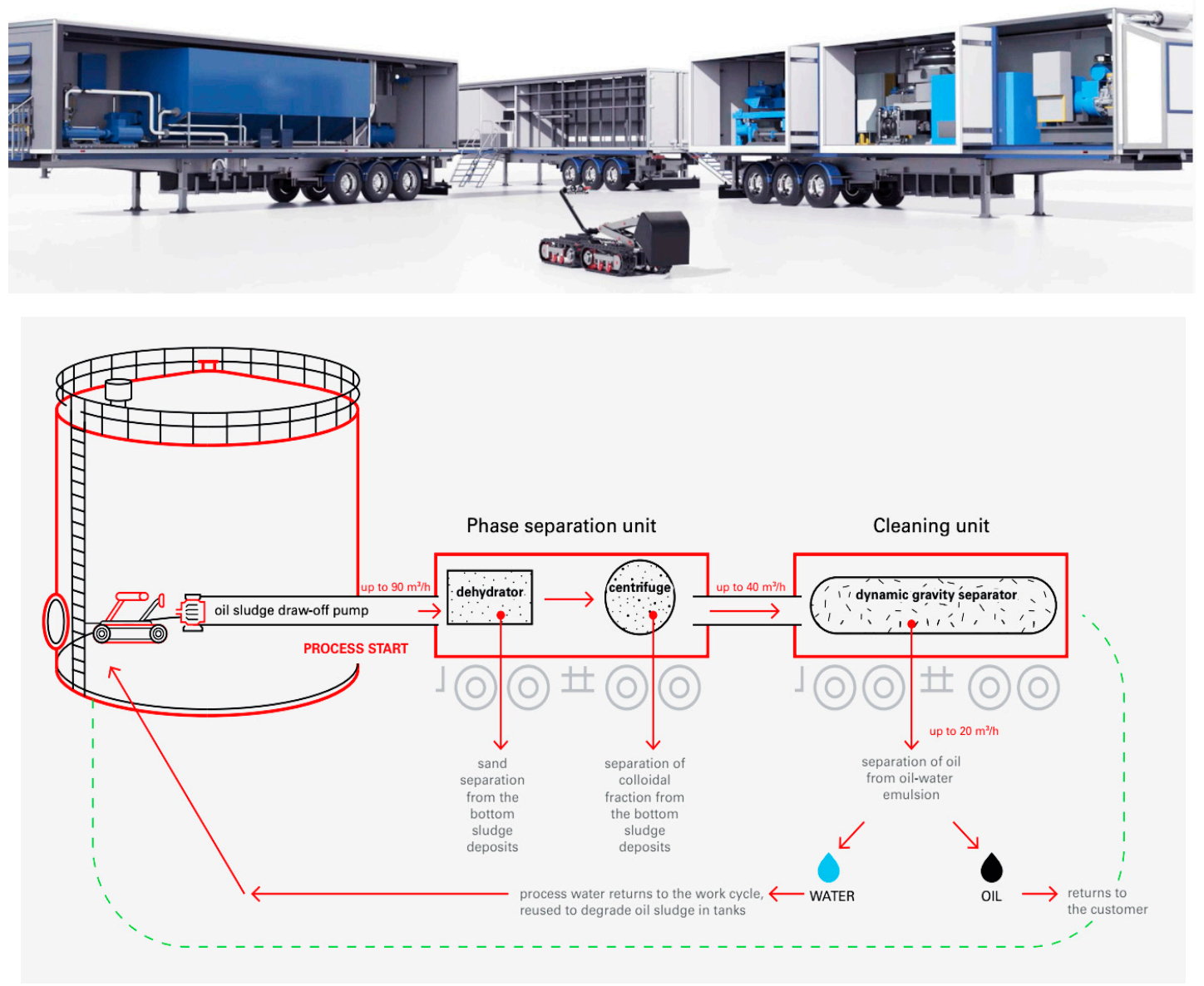

Figure 9. MIRRICO's MARTin robotic tank cleaning process [45,47].

\section{Results and Discussion}

\subsection{Performance of Cleaning Methods}

\subsubsection{Manual Cleaning}

A comparative calculation of the economic efficiency between manual and robotic methods for cleaning oil tanks developed by MIRRICO [49] provides some details on the cleaning time. From these data, the following table (Table 9) is formed that illustrates the cleaning time according to the process and the volume of the tank.

Table 9. Tank cleaning duration (days).

\begin{tabular}{cccccccc}
\hline Process/Tank Volume $\left(\mathbf{m}^{\mathbf{3}}\right)$ & $\mathbf{1 0 0 0}$ & $\mathbf{3 0 0 0}$ & $\mathbf{5 0 0 0}$ & $\mathbf{1 0 , 0 0 0}$ & $\mathbf{2 0 , 0 0 0}$ & $\mathbf{5 0 , 0 0 0}$ \\
\hline Manual cleaning & 8 & 10 & 15 & 25 & 45 & 60 \\
Robotic cleaning & 2 & 4 & 7 & 10 & 14 & 25 \\
\hline
\end{tabular}

It can be seen from the table above that the average cleaning time of the manual method is about 3 times longer than the robotic cleaning time. Therefore, from previous data about the minimum cleaning performance of robotic cleaning, which is $10 \mathrm{~m}^{3} / \mathrm{h}$, we conclude that the average performance for manual cleaning is $3.5 \mathrm{~m}^{3} / \mathrm{h}$. This performance is a result of several factors. Starting from the beginning, the system installation time is much longer than other methods as it requires many different auxiliary and cleaning equipment, such as water jetting equipment, pumps, vacuum trucks, shovels, tool warehouses, containers, portable dressing rooms, toilets, restaurant, offices, cranes, etc. Compared 
to automated systems, this method requires far more people who form a construction site rather than a cleaning system. Besides, the equipment used for manual cleaning is not concentrated in one module, as is the case with automated methods, because it is not used all year round for this purpose. After the installation of the worksite, another factor contributing to the long cleaning time is the hot recirculation of the product into the tank. This takes a considerable amount of time and is done to moisten (soften) the sludge to a degree to facilitate its suction. Also, another contributing factor is the time it takes to ventilate the interior of the tank so that it is freed from explosive concentrations, toxic gases, carbon monoxides, etc. Oxygen levels should increase and remain within satisfactory limits. All this is a 'gas-free' process and only after it has been certified by the appropriate department that it has been successfully executed (i.e., the interior is suitable for hosting human staff) do the personnel enter the tank for work.

Then, another parameter that has costs in time and efficiency is the final fluidization of the sludge by water pressures. Vacuum trucks cannot pump the sludge with their design suction rate (which can reach $30 \mathrm{~m}^{3} / \mathrm{h}$ ) because the sludge is never perfectly liquefied. This requires constant support from staff who apply high-pressure water jetting to continuously break up and fluidize the sludge, but this is limited because the large water supply creates significant waste that must be disposed of later, something that is both environmentally and cost undesirable. So, the efficiency of the vacuum truck to suck petroleum sludge out of the tank is estimated at $5 \mathrm{~m}^{3} / \mathrm{h} /$ vacuum truck. Using more than one vacuum truck and working $24 / 7$ is up to the customer, but this means more staff and costs. Finally, the quality of the cleaning after completion of the work is remarkable. Inspection and repairs can be carried out immediately, with the only disadvantage being that if the equipment is not handled properly during cleaning, there is a risk of damage to the inner parts of the tank.

\subsubsection{Automated (Non-Human-Entry-Mechanical) Cleaning}

\section{ORECO's BLABO System}

Regarding the case studies provided by the company for cleaning crude oil tanks, the average yield of this cleaning method is $6.6 \mathrm{~m}^{3} / \mathrm{h}$ working $24 / 7$ or $160 \mathrm{~m}^{3} /$ day otherwise. This performance includes the transfer of equipment, installation, tank preparation (nitrogen blanketing), sludge removal and removal of equipment from the tank after completion of work. Regarding the ability to recover hydrocarbons from the sludge, the recovery rate is estimated at $96.6 \%$, but nevertheless, it depends on the sludge content of hydrocarbons, which is most often $95 \%$.

It takes 7 days to install the system and the use of a crane is mandatory as many parts of the equipment must be lifted onto the roof of the tank. The equipment configuration without recycling consists of 3 containers ( $20 \mathrm{ft}$ ), and with the recycling module, consists of 8 containers ( $20 \mathrm{ft}$ ), which need to be unloaded from the trucks carrying them and installed on the ground, which requires the ground being level. The installation process can begin immediately after the tank is shut down because no hot recirculation of the stored product is required before cleaning (this is done via BLABO's jetting nozzles later), nor does the tank need to be gas-free, as in the first stage, no human personnel are required in the tank to remove the sludge. However, one major disadvantage that limits the range of application is that there is a need to have a stored diesel unit used for sludge liquefaction. Therefore, if there is no diesel tank nearby, then the jetting nozzles could not be supplied with cleaning media. The tank-cleaning machines clean effectively with no adverse effects on tank coatings, steam coils and other structures. This method offers maximum cleaning quality and inspection and repairs can be started directly. In the tank, after the application of cold tapping for the installation of the jetting nozzles, some permanent changes are made as holes are opened for the orifices to be installed. This is positive on the one hand because if this method is to be reused, it does not need to be repeated and considerable time will be lost. However, removal of material reduces the mechanical strength of the structure. 


\section{ZAOPIN Technologies COW System}

This system that falls into the category of automated cleaning methods competes with the BLABO process in the world market as the technology used is similar. The duration of installation and rigging of the equipment is 3 days, including the preparation of the tank for cleaning operations (tank blanketing with nitrogen). The equipment is stored in 4 containers which are carried by truck and the crane is necessary for the unloading and installation on the ground and in the tank. Also, the ground, as for the BLABO process, must be properly shaped. The method is applicable to floating and fixed roof tanks (including old riveted tanks) as well as to storage tanks with a volume of up to $150,000 \mathrm{~m}^{3}$. It provides complete desludging, independent of the thickness of the sludge. According to the specifications provided by the company [37], the following table (Table 10) is configured to provide information on system performance.

Table 10 shows that the average yield of this method based on the specifications of the system is $9.25 \mathrm{~m}^{3} / \mathrm{h}$ or $222 \mathrm{~m}^{3} /$ day with $24 / 7$ operation. This performance includes all phases of work from start to finish. Considering Table 7 in Section 3.3.2, which refers to the case studies, we observe an average performance of $8 \mathrm{~m}^{3} / \mathrm{h}$ or $192 \mathrm{~m}^{3} /$ day (24/7 operation) from start to finish. So, from the above results, we can see that the average performance is $8.6 \mathrm{~m}^{3} / \mathrm{h}$ or $206 \mathrm{~m}^{3} /$ day. The recycling capacity reaches $15 \mathrm{~m}^{3} / \mathrm{h}$. After water wash, all surfaces are ready for inspection and maintenance. The oil recovery ratio is up to $95 \%$ depending on the composition of sludge. A basic disadvantage, like in BLABO's process, is that diesel feed is constantly required.

Table 10. Zaopin technologies COW system performance.

\begin{tabular}{ccccc}
\hline Tank Data & Case 1 & Case 2 & Case 3 & Average Values \\
\hline Tank Volume $\left(\mathrm{m}^{3}\right)$ & 50,000 & 100,000 & 150,000 & 100,000 \\
Diameter $\left(\mathrm{m}^{1}\right)^{2}$ & 70 & 85 & 100 & 85 \\
Bottom Surface $\left(\mathrm{m}^{2}\right)^{2}$ & 3848 & 5674 & 7854 & 5792 \\
Sludge Content $\left(\mathrm{m}^{3}\right)^{3}$ & 2309 & 3405 & 4713 & 3476 \\
Cleaning Duration $($ Days $)(24 / 7)$ & 12 & 15 & 19 & 16 \\
Performance $\left(\mathrm{m}^{3} /\right.$ day) & 192 & 227 & 248 & 222 \\
Performance $\left(\mathrm{m}^{3} / \mathrm{h}\right)(24 / 7)$ & 8 & 9.46 & 10.3 & 9.25
\end{tabular}

${ }_{1}$ In order to calculate the estimated amount of sludge in the tank and to provide cleaning performance, the diameter was estimated in accordance with the volume. ${ }^{2}$ The bottom surface was calculated based on the diameter of the tank. ${ }^{3}$ The sludge volume was calculated considering the average sludge height $0.6 \mathrm{~m}$.

\section{KMT's MEGAMACS System}

The robotic cleaning offered by the MEGAMACS process leaves a very good impression on the world market. The configuration with the recycling module consists of only two semitrailers ( $40 \mathrm{ft})$ that can be easily transported by truck and installed on any ground in a very fast time compared to other methods, ranging from 4 to $8 \mathrm{~h}$. Cleaning can be started directly as blanketing of the tank with nitrogen is not necessary. The advantages it offers in terms of performance compared to competing methods are that it does not require a crane at any stage of operation, no permanent conversion to the tank, nor any special power supply from the unit, such as diesel, nitrogen, electricity, etc., as everything is autonomous. The fact that it does not need diesel power to fluidize the sludge enables it to be used in addition to downstream and in upstream plants.

Initially, it was specifically designed for crude oil storage tank cleaning, but today, the variety of applications can be seen below:

- Oil sludge pits and lagoon cleaning

- Catalysts storage tank cleaning

- Railroad tanker cleaning

- Cleaning of various vessels, barges, etc. 
The system for removing sludge from the tank has two efficiencies. The first is $6.7 \mathrm{~m}^{3} / \mathrm{h}$ or $161 \mathrm{~m}^{3} / \mathrm{d}$ in $24 / 7$ operation and involves the use of the robotic cannon. The second is $14.8 \mathrm{~m}^{3} / \mathrm{h}$ or $357 \mathrm{~m}^{3} / \mathrm{d} 24 / 7$ and concerns the use of the sludge extractor. Both performances include installing and removing equipment from the tank. The bottom sediment recycling capacity is $15 \mathrm{~m}^{3} / \mathrm{h}$, as seen for other methods. The system can clean tanks to the level of welding repairs. A disadvantage compared to the BLABO process is that there is no possibility of work performance while the level of bottom sediments is higher than hatch level. The sludge level inside the tank must be lowered below the hatch level in order to start the cleaning operations.

\subsubsection{Robotic Cleaning}

\section{MIRRICO's MARTin Oil Tech System}

This method is the most sophisticated one in the field of robotic cleaning because of the many advantages it offers over other methods. The equipment can be used in the cleaning of railway tanks, sludge collectors in oil refineries, as well as oil farms and gas-producing companies. The equipment is installed in 3 semitrailers ( $40 \mathrm{ft}$ ) and is transported by truck. It can be installed on any ground thanks to its flexible hydraulic system. It does not require blanketing of the tank and can operate in environments with temperatures down to $-35{ }^{\circ} \mathrm{C}$. Installation takes place in a very short time $(4-8 \mathrm{~h})$ and does not require the use of a crane. No permanent changes are made to the tank while the system is completely autonomous (no need for steam, water, electricity or cleaning media). Work can also be carried out even if the height of the mud in the tank is above the height of the manhole. Also, the cleaning done is so efficient that even the most difficult parts inside the tank can be cleaned up, eliminating the need for the final manual finishing clean required by all other methods. The following table (Table 11) has been created according to the times given in the presentation of the company [47].

Table 11. MIRRICO's MARTin system performance.

\begin{tabular}{cccccc}
\hline Tank Data & Case $\mathbf{1}$ & Case $\mathbf{2}$ & Case 3 & Case 4 & Average Values \\
\hline Volume $\left(\mathrm{m}^{3}\right)$ & 50,000 & 80,000 & 100,000 & 120,000 & 87,500 \\
Diameter $\left(\mathrm{m}^{1}{ }^{1}\right.$ & 70 & 80 & $\mathbf{8 5}$ & 90 & 82 \\
Bottom Surface $\left(\mathrm{m}^{2}\right)^{2}$ & 3848 & 5026 & 5674 & 6362 & 5228 \\
Sludge Content $\left(\mathrm{m}^{3}\right)^{3}$ & 2309 & 3016 & 3405 & 3817 & 3137 \\
Cleaning Duration $($ Days $)(24 / 7)$ & 12 & 20 & 25 & 30 & 22 \\
Performance $\left(\mathrm{m}^{3} /\right.$ day) & 192 & 151 & 136 & 127 & 152 \\
Performance $\left(\mathrm{m}^{3} / \mathrm{h}\right)(24 / 7)$ & 8 & 6.3 & 5.7 & 5.3 & 6.3 \\
\hline
\end{tabular}

${ }^{1}$ In order to calculate the estimated amount of sludge in the tank and to provide cleaning performance, the diameter was estimated in accordance with the volume. ${ }^{2}$ The bottom surface was calculated based on the diameter of the tank. ${ }^{3}$ The sludge volume was calculated considering the average sludge height $0.6 \mathrm{~m}$.

It is estimated from the table that the average performance of this method is $6.3 \mathrm{~m}^{3} / \mathrm{h}$ or $152 \mathrm{~m}^{3} / \mathrm{d}$ at 24/7. All this involves all the work from start to finish. The recycling capacity of the sludge is $40 \mathrm{~m}^{3} / \mathrm{h}$.

\subsection{Safety of Cleaning Methods}

\subsubsection{Manual Cleaning}

The manual method in the field of industrial tank cleaning is surrounded by the most disadvantages over all other methods in matters of occupational health and safety. This is mainly because the human being comes into direct exposure to a harmful environment throughout the course of cleaning the tank, which is highly likely to cause all kinds of accidents and diseases. The substances that the human body is exposed to are mainly volatile hydrocarbons, chemical solvents, heavy metals and petroleum. These pose the greatest risk when they come into direct contact with the skin or eyes, and when 
inhaled and swallowed. Even if excellent personal protection measures are granted to staff, they are not capable of being highly protective. Also, the confined, dark and muddy space inside the tank combined with the heavy equipment that must be manually operated makes the job very demanding while visibility is particularly difficult, leading to possible physical accidents due to exhaustion and adverse conditions. Furthermore, the atmosphere inside the tank is not constantly monitored by an automatic control system which in case of danger interrupts work or warns staff to stop and get out of the tank. So, the risk of having to be manualized by the operator at various intervals increases the risk. An additional hazard is compounded by the fact that the equipment used is not anti-explosive and certified to be used in tanks and confined spaces containing highly flammable and explosive substances, thereby creating the risk of explosions. Consequently, there is no positive evidence for this method in the field of hygiene and safety, and therefore it has begun to emerge from the world market and be replaced by automated or robotic methods.

\subsubsection{Automated (Non-Human-Entry-Mechanical) Cleaning}

This method is the next step after manual cleaning to improve safety conditions during the cleaning of oil tanks. The equipment is installed safely in an open atmosphere without explosive concentrations. The system with the jetting nozzles is fitted to the tank by cold tapping and liquefies the sludge into the tank by spraying cleaning media or water, replacing the manual spraying method from the inside of the tank. After the liquefaction, the sludge is easily sucked up from the existing nozzles of the tank, and no special drainage pipe is required to be carried inside the tank. The closed sludge drainage and treatment system combined with the inert atmosphere ensures maximum safety against fire and explosion. The atmosphere inside the tank is constantly monitored by an automatic control system and shuts down immediately if something is going to go wrong. At the stages of desludging and treatment, no one needs to enter the tank. In terms of safety, there is no disadvantage regarding the manual cleaning, but compared with robotic cleaning, the only disadvantage is that at the end of the process, it may be necessary to manually remove some sand or oil-free rust scales from the inside of the tank. Although this is carried out inside a permit-required confined space, it is done without the use of breathing apparatus because the tank at this stage is fully clean from hydrocarbons.

\subsubsection{Robotic Cleaning}

Robotic cleaning meets all safety requirements in line with current regulations and has many advantages over all other methods, as shown below:

- No personnel entry into the tank is required at any stage of the process

- All equipment is hydraulically driven

- No electrical components inside the tank

- Tank blanketing is not required

- It does not generate static electricity

- The system can be installed up to $150 \mathrm{~m}$ away from the tank

- It has a common ground with the tank and shuts down if there is a problem in the circuit

- The system is stored into semitrailers which are very well insulated and is equipped with air conditioning, protecting the staff from very low or high temperatures.

Regarding safety, for all the above reasons and because it shows no disadvantage compared to other methods, it is by far the safest cleaning method available in the market.

\subsection{Environmental Impact of Cleaning Methods}

\subsubsection{Manual Cleaning}

In addition to the disadvantages of manual cleaning in the areas of safety and efficiency, it also has serious environmental impacts. This is mainly because the cleaning system is an open circuit to the 
environment and there is always a high risk of petroleum wastes contamination with it. All means used (such as equipment, personal protective equipment, tools, etc.) come into direct contact with hydrocarbons, which can be transported directly or indirectly to the environment. Also, the system does not have a unit that purifies and recycles the water used to liquefy the sludge in the tank compared to automated methods. This increases the water consumption and thus the volume of waste. As for the management of the removed sludge, this is (in the best case) handled by a waste management company, so is temporarily stored in open cement pits before the receipt. The time between storage and loading of the sludge gives time for the light hydrocarbons that are in its composition to evaporate, thereby significantly contaminating the atmosphere. Also, if the cement ponds or any other storage space is not properly covered, during rainfalls, the water entering it will significantly increase the volume of waste and thus the management costs.

\subsubsection{Automated (Non-Human-Entry-Mechanical) Cleaning}

In relation to the manual method, the system removes and processes the sludge through a closed circuit that prevents any hydrocarbon emissions to the environment. Waste to be disposed of in the environment after final treatment contains negligible amounts of hydrocarbons. Water, for example, contains hydrocarbons $<100 \mathrm{ppm}$, while solid wastes $\sim 5 \%$. The oil is returned to the customer for sale or re-stored in another tank. The equipment is powered by electricity. It is a very environmentally friendly method.

\subsubsection{Robotic Cleaning}

The advantages of robotic cleaning are like automatic. It makes no difference as far as sludge removal and treatment is concerned. Everything is done in a closed circuit and the waste deposited is negligible. However, instead of electricity, it uses oil to generate energy, presenting some emissions to the environment.

\subsection{Cost of Cleaning Methods}

\subsubsection{Manual Cleaning}

The first part of the cost of this method relates to the contracting staff used to remove the sludge from the inside of the tank. This staff is large in number because they have to be constantly recycled due to regulations requiring them to stay inside the tank only for short time periods for hygiene and safety reasons. In addition, people working inside the tank need to be monitored throughout the work by man-way watchers outside the tank. Also, a rescue team must always be available to intervene immediately in case of an emergency. Overtime, night work, weekends and public holidays significantly increase costs. Also, as the work is carried out within the permit-required confined space, it is extremely dangerous and safety officers must be on site until the end of the work to avoid any accident. Renting a vacuum truck for pumping sludge from inside the tank is an additional cost. The second part of the cost relates to the management of sludge after removal from the tank. Because the sludge has not been treated at all, it is full of hydrocarbons, water and solid residues. The addition of large quantities of water to liquefy it prior to removal from the tank has significantly increased its volume. Therefore, the cost of disposal is greater than that of removal from the tank. According to the MIRRICO's MARTin data, the cost of cleaning using the manual method is shown below:

- Tank cleaning cost: $100 \$ / \mathrm{m}^{3}$

- Cost of disposal of oil sludge: $127.5 \$ / \mathrm{m}^{3}$

- Total cost of tank cleaning: $227.5 \$ / \mathrm{m}^{3}$

It should be noted that in upstream plants where crude oil is stored temporarily until it is shipped to a refinery, less emphasis is placed on the separation of water and solid particles from the oil composition. For this reason, they do not spend extra money on sludge treatment and deposition after 
cleaning. So, the sludge recovered from cleaning is added to another tank in operation and sold with crude oil.

\subsubsection{Automated (Non-Human-Entry-Mechanical) Cleaning}

Compared to manual, the cost of this method is higher, and this is mainly because there is no expense for sludge deposition as the quantities after treatment are almost zero. Furthermore, the many advantages it offers in terms of performance, safety, environment and technology increase the cost of cleaning. Although the cost of cleaning with the BLABO system is $254.25 \$ / \mathrm{m}^{3}$, this plays a very minor role as the revenues from the return of oil to the customer outweigh the cleaning costs. According to an ORECO's case study [50], a 18,500 $\mathrm{m}^{3}$ tank in Fawley Refinery in the UK, which contained cat slurry, changed from manual to automated tank cleaning using the BLABO method. The cleaning time was 15 days, and from the total sludge content that was $1832 \mathrm{~m}^{3}, 1791 \mathrm{~m}^{3}$ of oil was recovered. The recovered oil sold for $60 \$ / \mathrm{bbl}$ and its total value was $675,900.00 \$$. It is thus noted that the revenue from oil recovered from the sludge was more than the expenses required for cleaning $(465,786.00 \$)$ and saved time and money.

\subsubsection{Robotic Cleaning}

Robotic cleaning is less expensive than manual and automatic cleaning. Although the cleaning process is like the automatic method, some details make the difference in the final cost. Transportation costs are less as the equipment is installed in just 3 semitrailers compared to the automatic equipment in 8 containers. No crane rental is required, and installation takes only $4-8 \mathrm{~h}$ instead of 7 days. It is also very important that no personnel are required to enter the tank at any stage of cleaning. In addition, it has the highest bottom sediment recycling capacity of all other methods $\left(40 \mathrm{~m}^{3} / \mathrm{h}\right)$. The cleaning cost of this method is $154.25 \$ / \mathrm{m}^{3}$ [46].

\section{Conclusions}

Commercial cleaning methods are divided into manual, automated-mechanical and robotic. The main criteria for evaluating a cleaning method focus on four factors, such as safety, performance, environmental impact and cost. In this article, some different cleaning methods were discussed: (i) manual, (ii) BLABO (automated-mechanical), (iii) COW (automated-mechanical), (iv) MEGAMACS (automated-mechanical) and (v) MARTin (robotic). Some very important conclusions were:

- The faster cleaning system is the automated (mechanical) MEGAMACS with sludge extractor. All other automated and robotic systems in terms of time present very little deviation from each other and provide the same cleaning quality. Manual cleaning ends up being the slowest and most painful cleaning method.

- As far as safety is concerned, the MARTin robotic cleaning system reaches the top, being the only exception where the presence of people inside the tank is not necessary at any stage of cleaning. In all other methods, entering the tank, at one of the cleaning stages, is mandatory.

- The most dangerous and harmful cleaning method is the manual one, in which the presence of people inside the tank is required from the beginning to the end of the process.

- From an environmental point of view, all automated (mechanical) and robotic systems have closed loop cleaning circuits and a very efficient hydrocarbon recovery system. The only method that cleans with an open system and does not recycle the produced waste is the manual one, which is significantly burdening not only people but also the environment.

- MARTin and MEGAMACS have the lowest cleaning costs, while BLABO is the most expensive.

- The modern need in the field of industrial tank cleaning focuses on inventing methods that clean in a short time, with an automated system that does not require people to enter the interior of the tank, with the ability to recover almost all hydrocarbons from the wastes in the lower cost.

The detailed results from the comparison of the cleaning methods are summarized in Table 12. 
Table 12. Comparative table of oil tank cleaning methods.

\begin{tabular}{|c|c|c|c|c|c|c|}
\hline \multirow{2}{*}{$\begin{array}{l}\text { Indicator/Company } \\
\text { Equipment }\end{array}$} & \multirow{2}{*}{$\begin{array}{c}\text { MIRRICO } \\
\text { MARTin }\end{array}$} & \multicolumn{2}{|c|}{ KMT } & \multirow{2}{*}{$\begin{array}{l}\text { ORECO } \\
\text { BLABO }\end{array}$} & \multirow{2}{*}{$\frac{\text { ZAOPIN TECH. }}{\text { COW }}$} & \multirow[b]{2}{*}{ Manual } \\
\hline & & $\begin{array}{l}\text { MEGAMACS } \\
\text { Robotic Cannon }\end{array}$ & $\begin{array}{l}\text { MEGAMACS } \\
\text { Extractor }\end{array}$ & & & \\
\hline Tank cleaning technology & Robotic cleaning & \multicolumn{4}{|c|}{ Automated (Mechanical) Cleaning } & Manual cleaning \\
\hline Performance $\left(\mathrm{m}^{3} / \mathrm{h}\right)$ & 6.3 & 6.7 & 14.8 & 6.6 & 8.6 & 3.5 \\
\hline Sludge recycling capacity $\left(\mathrm{m}^{3} / \mathrm{h}\right)$ & 40 & \multirow{2}{*}{\multicolumn{2}{|c|}{$\begin{array}{c}15 \\
\text { Hot Water }\end{array}$}} & 15 & 15 & $\mathrm{~N} / \mathrm{A}$ \\
\hline Required Feeding (Cleaning media) & Hot water & & & Diesel & Diesel & Manual water jetting \\
\hline Personnel inside the tank & Not required & At intervals & All the Time & At final stage & At final stage & All the time \\
\hline Tank Blanketing with Nitrogen & Not required & Required & Not required & Required & Required & Not required \\
\hline Anti-explosive equipment & Yes & Yes & Yes & Yes & Yes & No \\
\hline Atmosphere Monitoring & Automatic all time & Automatic All Time & Automatic All Time & Automatic all time & Automatic all time & Manual at intervals \\
\hline Sludge circuit type & Closed loop & \multicolumn{2}{|c|}{ Closed loop } & Closed loop & Closed Loop & Open loop \\
\hline Energy source & Diesel & \multicolumn{2}{|c|}{ Diesel } & Electricity & Electricity & Electricity/Diesel \\
\hline Oil recovery ratio & $95 \%$ & \multicolumn{2}{|c|}{$95 \%$} & $96.6 \%$ & 95 & N/A \\
\hline Total costs $\left(\$ / \mathrm{m}^{3}\right)$ & 154.25 & \multicolumn{2}{|c|}{154.25} & 254.25 & Unknown & 227.5 \\
\hline
\end{tabular}


Author Contributions: methodology, A.C. and G.Z.K.; writing-original draft preparation, A.C. and G.Z.K.; writing-review and editing, supervision, G.Z.K.; All authors have read and agreed to the published version of the manuscript.

Funding: This research received no external funding.

Acknowledgments: The authors thank the "MSc in Oil and Gas Technology" (Department of Chemistry, School of Science, International Hellenic University, Kavala, Greece) for the general support.

Conflicts of Interest: The authors declare no conflict of interest.

\section{References}

1. Energy East Pipeline Ltd. Tank Terminals-General Design. Consol. Appl. 2016, 6, 16.

2. PetroWiki. Floating Roof Tanks. Available online: https://petrowiki.org/Floating_roof_tanks (accessed on 4 March 2020).

3. Thanh, N.X.; Hsieh, M.; Philp, R.P. Waxes and asphaltenes in crude oils. Org. Geochem. 1999, 30, 119-132. [CrossRef]

4. Kleinfeld, M.; Feiner, B. Health Hazards Associated with Work in Confined Spaces. J. Occup. Environ. Med. 1966, 8, 358-364.

5. Scott, S. Conventional and Non Man-Entry Tank Desludging and Cleaning. Available online: http: //scott7.com/tank-desludging-cleaning/ (accessed on 7 March 2020).

6. Philemon Ze Bilo'o, M.B.N. Christelle Solange Jessie Ekoka, Characterization of Oily Sludge from Cameroon Petroleum Refinery. Int. J. Emerg. Eng. Res. Technol. 2016, 4, 34-38.

7. PennState College of Earth and Mineral Sciences Chemical Constitution of Crude Oil. Available online: https://www.e-education.psu.edu/fsc432/node/5 (accessed on 3 March 2020).

8. Demirbas, A.; Alidrisi, H.; Balubaid, M.A. API Gravity, Sulfur Content, and Desulfurization of Crude Oil. Pet. Sci. Technol. 2015, 33, 93-101. [CrossRef]

9. URET Distillation of Crude Oil \& Oil Products. Available online: https://uret.com.tr/en/uret-blog-en/ distillation-of-crude-oil-oil-products/ (accessed on 4 March 2020).

10. Leontaritis, K.J.; Ali Mansoori, G. Asphaltene deposition: A survey of field experiences and research approaches. J. Pet. Sci. Eng. 1988, 1, 229-239. [CrossRef]

11. Carnahan, N.; Salager, J.L.; Anton, R. Effect of Resins on Stability of Asphaltenes. In Offshore Technology Conference; Offshore Technology Conference: Houston, TX, USA, 2007; p. 9.

12. Izquierdo, A.; Rivas, O. A Global Approach to Asphaltene Deposition Problems. In International Symposium on Oilfield Chemistry; Society of Petroleum Engineers: Houston, TX, USA, 1997; p. 8.

13. Speight., J.G. Petroleum Asphaltenes-Part 1: Asphaltenes, Resins and the Structure of Petroleum. Oil Gas Sci. Technol. Rev. D'ifp Energ. Nouv. Inst. Français Du Pétrole. 2004, 59, 467-477. [CrossRef]

14. WPenvironmental SOR (Sludge Oil Recovery Unit). Available online: https://www.wpenvironmental.com/ sludge-oil-recovery-unit/\#iLightbox[gallery_image_1]/0 (accessed on 4 March 2020).

15. Al-Futaisi, A.; Jamrah, A.; Yaghi, B.; Taha, R. Assessment of alternative management techniques of tank bottom petroleum sludge in Oman. J. Hazard. Mater. 2007, 141, 557-564. [CrossRef] [PubMed]

16. Heidarzadeh, N.; Gitipour, S.; Abdoli, M.A. Characterization of oily sludge from a Tehran oil refinery. Waste Manag. Res. 2010, 28, 921-927. [CrossRef] [PubMed]

17. Johnson, O.A.; Affam, A.C. Petroleum sludge treatment and disposal: A review. Environ. Eng. Res. 2019, 24, 191-201. [CrossRef]

18. Mansur, A. Recovery and Characterization of Oil from Waste Crude Oil Tank Bottom Sludge from Azzawiya Oil Refinery in Libya. J. Adv. Chem. Eng. 2015, 5, 05. [CrossRef]

19. SERVICES, W.O. Storage Tank Inspections. Available online: https://willacyoil.com/petrochemical-oilrefinery-services/storage-tank-inspections-non-destructive/ (accessed on 4 March 2020).

20. Institution, A.P. Requirements for Safe Entry and Cleaning of Petroleum Storage Tanks; API Publishing Services: Washington, DC, USA, 2018.

21. API. Guidelines and Procedures for Entering and Cleaning Petroleum Storage Tanks. In ANSI/API Recommended Practice 2016; API Publishing Services: Washington, DC, USA, 2006.

22. NuovaSaimar Storage Tank Cleaning-Traditional Tank Cleaning Method. Available online: https://www. nuovasaimar.it/en/our-services/tank-cleaning/ (accessed on 4 March 2020). 
23. TRADEBE TRADITIONAL TANK CLEANING. Available online: https://www.tradebeindustrialservices. com/traditional-tank-cleaning (accessed on 3 March 2020).

24. Westates Technologies, I. Complete Tank Cleaning \& Sludge Removal Solutions. Available online: http: //www.alltankcleaning.com/ (accessed on 3 March 2020).

25. Al-Dousary, S.; Dharan, G.P.T. Implementation Of Non-man Entry Technology-An Automated Technology for De-sludging \& Cleaning of Tanks. In SPE Kuwait Oil and Gas Show and Conference; Society of Petroleum Engineers: Mishref, Kuwait, 2015; p. 9.

26. Oreco Tank Cleaning Process and Services. Available online: https://www.oreco.com/solutions/crude-oiltank-cleaning/the-tank-cleaning-process/ (accessed on 3 March 2020).

27. SlideShare Blabo Process. Available online: https://www.slideshare.net/Oreco/blabo-process (accessed on 3 March 2020).

28. Tank Cleaning Services, The Blabo Process. Available online: https://www.oreco.com/solutions/crude-oiltank-cleaning/the-tank-cleaning-process/ (accessed on 3 March 2020).

29. Oreco Suction Module. Available online: https://www.oreco.com/solutions/crude-oil-tank-cleaning/howblabo-works/suction-module/ (accessed on 3 March 2020).

30. Oreco Recirculation Module. Available online: https://www.oreco.com/solutions/crude-oil-tank-cleaning/ how-blabo-works/recirculation-module/ (accessed on 3 March 2020).

31. Oreco Top Entry-Single Nozzle Sweeper for Efficient Tank Cleaning. Available online: https://www.oreco. com/media/1427/190321_oreco_sns_top_entry_brochure.pdf (accessed on 13 April 2020).

32. Oreco Separation Module. Available online: https://www.oreco.com/solutions/crude-oil-tank-cleaning/howblabo-works/separation-module/ (accessed on 3 March 2020).

33. Oreco Oil Skimming Module. Available online: https://www.oreco.com/solutions/crude-oil-tank-cleaning/ how-blabo-works/skimming-module/ (accessed on 3 March 2020).

34. Yayla, S.; Sabah, S.; Olcay, A. Engineering Applications of Computational Fluid Mechanics Numerical investigation of coalescing plate system to understand the separation of water and oil in water treatment plant of petroleum industry Numerical investigation of coalescing plate system to understand the separation of water and oil in water treatment plant of petroleum industry. Eng. Appl. Comput. Fluid Mech. 2017, 11, 184-192.

35. Oreco Customer Cases. Available online: https://www.oreco.com/references/customer-cases/ (accessed on 4 March 2020).

36. VAOS Automated Hydrocarbon Recovery and Tank Cleaning (AHRTC) Services. Available online: http://www.vaos.com/en/services/services/4/automated-hydrocarbon-recovery-and-tank-cleaningahrtc-services.htm (accessed on 18 March 2020).

37. Technologies, Z. Crude Oil Tank Cleaning Systems. Available online: http://www.zp-tec.com/products/ crude-oil-tank-cleaning (accessed on 3 March 2020).

38. KMT Mega Macs Tank Cleaning for Crude and Sludge Oil. Available online: https://kmt-tankcleaning.com/ megamacs (accessed on 17 March 2020).

39. Cleaning, K.-T. CUTTING-EDGE, MOBILE SLUDGE REMOVAL AND PROCESSING SYSTEM. Available online: https://kmt-tankcleaning.com/process (accessed on 15 March 2020).

40. KMT Mega Macs Auxillary Equipment. Available online: https://kmt-tankcleaning.com/aux-equipment (accessed on 17 March 2020).

41. Suleiman, O.M.E.; Osman, M.Y.; Kassala, S. Deflection of Rectangular Laminated Composite Plates using Dynamic Relaxation Method; LAPLAMBERT Academic Publishing, Member of Omni Scriptum Publishing Group: Latvia, Germany, 2007; ISBN 978-3-330-33164-8.

42. Amirante, P.; Clodoveo, M.L.; Leone, A.; Tamborrino, A.; Patel, V.B. Chapter 10-Influence of Different Centrifugal Extraction Systems on Antioxidant Content and Stability of Virgin Olive Oil. In Olives and Olive Oil in Health and Disease Prevention; Preedy, V.R., Watson, R.R., Eds.; Academic Press: San Diego, CA, USA, 2010; pp. 85-93.

43. Sanpeng, D.; Xiaoli, X.; Chongning, L.; Xinghui, Z. Research on the oil tank sludge cleaning robot system. In Proceedings of the 2010 International Conference on Mechanic Automation and Control Engineering, Wuhan, China, 26-28 June 2010.

44. Group, A.T.K. Equipment Set for the Remotely-Controlled Removal of Sludge from Oil Tanks. Available online: https://www.adroctech.com/ (accessed on 14 March 2020). 
45. MARTin, MARTin-Innovative solution for no-man entry cleaning of tanks. Available online: https://www. mirrico.ru/en/services-products/products/robotic-method-of-stripping-petrochemical-equipmen (accessed on 14 March 2020).

46. StockExpo MARTIN-Mobile Robotic Tank Cleaning Solution. Available online: https://www.stocexpo.com/ en/products/martin-mobile-robotic-tank-cleaning-solution/ (accessed on 19 March 2020).

47. Tech, M.O. Martin: Innovative Robotic. Unit for Cleaning Oil Tanks. Available online: https://martinoil.tech/ (accessed on 14 March 2020).

48. MIRRICO Robotic Cleaning Method of Oilfield Equipment. Available online: https://www.mirrico.ru/en/ services-products/products/robotic-method-of-stripping-oil-field-equipment-fr/\#technologies (accessed on 19 March 2020).

49. MIRRICO Comparative Calculation of the Economic Efficiency of Manual and Robotic Methods for Cleaning Oil Tanks. Available online: https://www.mirrico.ru/en/services-products/products/robotic-method-ofstripping-oil-field-equipment-fr/\#calc (accessed on 20 March 2020).

50. ORECO Changing from Manual to Automated Tank Cleaning Saved Time and Money. Available online: https://www.oreco.com/media/1093/cases-fawley-uk.pdf (accessed on 29 March 2020).

(C) 2020 by the authors. Licensee MDPI, Basel, Switzerland. This article is an open access article distributed under the terms and conditions of the Creative Commons Attribution (CC BY) license (http://creativecommons.org/licenses/by/4.0/). 